\title{
Source-oriented model for air pollutant effects on visibility
}

\author{
A. Eldering \\ Civil and Environmental Engineering, University of Iowa, Iowa City \\ G. R. Cass \\ Environmental Engineering Science Department, California Institute of Technology, Pasadena
}

\begin{abstract}
A source-oriented model for air pollutant effects on visibility has been developed that can compute light scattering, light extinction, and estimated visual range directly from data on gas phase and primary particle phase air pollutant emissions from sources. The importance of such a model is that it can be used to compute the effect of emission control proposals on visibility-related parameters in advance of the adoption of such control programs. The model has been assembled by embedding several aerosol process modules within the photochemical trajectory model previously developed for aerosol nitrate concentration predictions by Russell et al. [1983] and Russell and Cass [1986]. These modules describe the size distribution and chemical composition of primary particle emissions, the speciation of organic vapor emissions, atmospheric chemical reactions, transport of condensible material between the gas and the particle phases, fog chemistry, dry deposition, and atmospheric light scattering and light absorption. Model predictions have been compared to observed values using 48-hour trajectories arriving at Claremont, California, at each hour of August 28, 1987, during the Southern California Air Quality Study. The predicted fine particle concentration averages $62 \mu \mathrm{g} \mathrm{m}^{-3}$ compared to an observed value of $61 \mu \mathrm{g} \mathrm{m}^{-3}$, while predicted PM10 concentrations average $102 \mu \mathrm{g} \mathrm{m}^{-3}$ compared to an observed average of $97 \mu \mathrm{g} \mathrm{m}^{-3}$. The size distribution and chemical composition predictions for elemental carbon, sulfate, and sodium ion agree with observations to within plus or minus a few micrograms per cubic meter, while ammonium and nitrate concentrations are underpredicted by the base case model by 3 to $7 \mu \mathrm{g} \mathrm{m}^{-3}$ on average. Light-scattering coefficient values are calculated from the predicted aerosol size distribution and refractive index, and the model predictions agree with measured values on average to within $19 \%$. The advantages and limitations of the modeling procedure are discussed.
\end{abstract}

\section{Introduction}

Visibility problems exist both in cities like Los Angeles and Denver and in more rural areas such as California's San Joaquin Valley that need to be understood at a level where emission controls applied at air pollutant sources can be studied to determine the resulting changes in visual range. Several approaches are available that could be used to link source emissions to visual air quality. The simplest of these is the use of speciated rollback air quality models linked to empirical visibility models [National Research Council (NRC), 1993] in which changes in light scattering and absorption in the atmosphere by major particulate species such as sul-

Copyright 1996 by the American Geophysical Union.

Paper number 95JD02928.

0148-0227/96/95JD-02928\$09.00 fates, nitrates, and carbon particles are taken to be directly proportional to the changes in source emissions of chemically similar precursors. In such models, aerosol sulfate concentrations would be assumed to change in proportion to gas phase $\mathrm{SO}_{2}$ emissions, and the effect of sulfate particles on light scattering would be estimated from statistical analysis of historical data sets on atmospheric light scattering in relation to day-to-day changes in aerosol sulfate concentrations, for example. Receptor-oriented statistical models that relate emissions to air quality also have been applied to visibility problems, including techniques based on principal components analysis [Pitchford and Pitchford, 1985], factor analysis [Stevens et al., 1984], and a semi-empirical methodology proposed by Zannetti et al. [1990, 1993].

Alternatively, mechanistic models can be envisioned that rely on a description of the size distribution and chemical composition of particulate matter emissions at their source plus the emissions of gaseous aerosol pre- 
cursors. These emissions are tracked as they undergo atmospheric transport, chemical transformations leading to gas-to-particle conversion in the atmosphere, and dry deposition, resulting in predictions of the size distribution and chemical composition of the atmospheric particles and gases at downwind receptor sites. This information on particle size distribution and chemical composition then could be used to support light extinction calculations based on Mie theory. Many of the existing mechanistic models that focus on visibility impairment are formulated as plume models. Eltgroth and Hobbs [1979] developed a mechanistic plume model and applied it to light scattering by a power plant plume. Reactive plume model development continues with the work of Seigneur et al. [1983, 1984] and White et al. [1985] . More recently, Hudischewskyj and Seigneur [1989] assembled a reactive plume model with thoroughly tested components, including the carbon bond III chemical mechanism (CBM III) [Whitten et al., 1980] and aerosol dynamics calculations based on the MARS aerosol thermodynamics code [Saxena et al., 1986].

Mechanistic models that relate pollutant emissions to visual air quality that can be applied to multiple source regional air quality problems could be assembled from available components $[N R C, 1993]$. At the heart of such models would be an aerosol processes model that accepts as inputs the size distribution and chemical composition of primary particle emissions from sources plus the emissions of reactive gases and then calculates the evolution of the aerosol size distribution and chemical composition as gas-to-particle conversion processes take place. Light scattering and absorption calculations based on that aerosol size and composition distribution would follow. Such models could be formulated in either a Lagrangian or an Eulerian coordinate system. Examples of underlying emissions-to-air quality models upon which such visibility models could be based can be identified. Mechanistic Lagrangian trajectory models for secondary aerosol formation begin with the aerosol nitrate model of Russell et al. [1983] and Russell and Cass [1986] and have evolved to treat secondary sulfates, secondary organics and aerosol size distribution calculations [Pilinis and Seinfeld, 1987; Pilinis et al., 1987; Pandis et al., 1992a, b, 1993]. Eulerian grid-based chemically reactive air shed models that could be used as the basis for future comprehensive aerosol processes models have been reviewed by Seigneur [1994] and by the National Research Council $[N R C, 1993])$. These include the regional acid deposition model (RADM II) [Chang et al., 1987, 1991], the acid deposition and oxidant model (ADOM) [Venkatram et al., 1988], the sulfur transport Eulerian model II (STEM II) [Carmichael et al., 1986, 1991], the regional oxidant model (ROM) [Lamb, 1982], the regional transport model III (RTM-III) [Liu et al., 1984], the urban air shed model (UAM/PARIS) [Reynolds et al., 1973, 1979; Seigneur et al., 1983], the California Institute of Technology model (CIT) [McRae et al., 1982; Russell et al., 1988; Pilinis and Seinfeld, 1988], the Livermore regional air quality model (LIRAQ) [MacCracken et al.,
1978; Penner and Connell, 1987], and the CALGRID model [Yamartino et al., 1992]. Of these, the CIT and UAM/PARIS models are capable of size-distributed aerosol chemical calculations using a sectional representation of the aerosol; the RADM II model uses lognormal size distributions to represent aerosols; STEM II can represent sulfate and nitrate aerosol formation but not size distributions, and the ADOM model tracks sulfate aerosol production. The remaining models would require extensive additions to incorporate aerosol chemistry and aerosol mechanics calculations into the underlying computer codes. While work is under way to apply Eulerian models to obtain size-distributed aerosol concentration predictions, model applications that predict secondary aerosol concentrations but not size distributions [e.g., Russell et al., 1988; Middleton and Burns, 1991] are judged by the $N R C$ [1993] to be at the current state of the art in most practical situations.

The purpose of the present work is to formulate a mechanistic model for the prediction of atmospheric light scattering, light absorption, and visual range that is driven directly by data on pollutant source emissions and meteorological observations. Such mechanistic models can be used to study the nonlinear chemistry involved in gas-to-particle conversion processes in ways that are not possible using simple linear rollback models. The model developed here will be tested using experimental data on size-distributed particulate matter both in ambient air and in source emissions and data on visibility-related parameters collected specifically for the purpose of supporting such a mechanistic air quality and visibility model. The ambient observations are from the 1987 Southern California Air Quality Study (SCAQS), while the source emissions measurements are those of Hildemann et al. [1991a, b]. Areas where limited input data still remain will be identified in an effort to guide the design of future field experiments intended to support such models.

\section{Conceptual Formulation of the Problem}

Consider an air parcel containing particulate matter corresponding to remote background concentrations. It contains low concentrations of ionic material such as sea-salt and sulfates, dilute combustion aerosols, natural organic aerosols, and possibly some soil dust. The air parcel then encounters an urban area where primary aerosol from fuel combustion and other human activities is inserted. The combined background plus primary particulate matter emissions become the "seed aerosol" on which condensation and heterogenous reaction processes take place. Over time, material is transferred from the gas phase to the particle phase (or vice versa), limited either by the rate of gas phase formation of condensible species or by the kinetic considerations of mass transfer rates or, alternatively, limited by having reached thermodynamic equilibrium between the gas and the particle phase. Species transferred in this manner include water vapor, ammonia, nitric acid vapor, hydrochloric acid vapor, sulfuric acid, and condensible organic vapors. In general, in a polluted environment, secondary sulfates, nitrates, and organics accumulate 
on the primary seed particles, while $\mathrm{HCl}$ derived from sea-salt chloride may be liberated from some particles [Eldering et al., 1991].

Urban aerosols are sufficiently dilute that coagulation is not of major practical importance. In particle sizes larger than about $0.1-\mu \mathrm{m}$ particle diameter, particle number counts arising from background and new primary emissions are nearly conserved, modified only by removal by wet or dry deposition. Removal processes are slow enough that fine aerosols have an atmospheric lifetime of approximately 3-5 days. Therefore a model that hypothetically follows single particles as they evolve in the presence of condensation, heterogeneous reaction, and deposition is possible.

If the seed particles, with their accumulation of secondary material, enter a condition where fog would form, particles larger than a critical size determined by particle composition and the ambient water vapor supersaturation are activated. Those particles grow rapidly, and enough water accumulates to permit aqueous phase reactions in which $\mathrm{SO}_{2}$ dissolved in droplets can be oxidized by species such as $\mathrm{H}_{2} \mathrm{O}_{2}$ and $\mathrm{O}_{3}$ scavenged from the photochemical smog contained in the surrounding gas phase. Dissolved $\mathrm{SO}_{2}$ also could be oxidized by oxygen in the presence of metal catalysts. If the fog evaporates, the fog droplets attempt to dry out, leaving in their place a smaller nucleus of the nonvolatile materials that were once contained in the fog drops. Meanwhile, sedimentation and other dry deposition processes remove particles from the system. For the air parcel as a whole, particles grow in size and new particles accumulate as long as fresh emissions exceed the rate of removal processes.

By tracking the background and primary seed particles and pollutant gases as they evolve in the air parcel, a model can be constructed for predicting the number concentration, size distribution, and chemical composition of the aerosol that results with sufficient detail that light scattering and absorption calculations can be performed via Mie theory. A model that connects source emissions to light scattering and absorption by particles, when added to light scattering by air molecules and light absorption by $\mathrm{NO}_{2}$, results in a model for the effect of source emissions on the atmospheric extinction coefficient as a function of wavelength. This model for the extinction coefficient can be used to predict the effect of emission changes on visual range via Koschmieder's formula [Middleton, 1952] and can be used to generate full color photographs of the effect of emission changes based on the visual character of a scene using imageprocessing-based visibility models like those of Eldering et al. [1993].

Since we describe a process that starts with single primary particles and follows their evolution within an air parcel, it is logical to begin with a Lagrangian trajectory model for the air parcel, especially in cases where a serious visibility reduction problem is to be studied having a visual range of only a few kilometers, consistent with the dimensions of the air parcels tracked by such a trajectory model. Within that trajectory model, we seek to embed a model for the background aerosol, a model for the primary aerosol source emissions, a photochemical gas phase mechanism and emissions model that will propagate aerosol precursor formation (e.g., $\mathrm{HNO}_{3}$ production) and oxidant production (e.g., $\mathrm{O}_{3}$, $\mathrm{H}_{2} \mathrm{O}_{2}$ production), a model for the diffusion of gases to and from the particle phase, a fog chemistry model, a dry deposition module, and a light-scattering code. Such components are available from a number of prior studies or from experimental work performed in support of the present model construction effort. The remainder of this paper describes the assembly of the above pieces of the visibility modeling system into an integrated whole. The model then will be tested by application to source emission data and atmospheric data taken in southern California.

\section{Mathematical Modeling of Air Pollutant Effects on Visibility}

A Lagrangian formulation of the atmospheric diffusion equation is employed in this work, as described by Russell et al. [1983] with the changes described below. The general form of the atmospheric diffusion equation employed by Lagrangian trajectory models is

$$
\begin{gathered}
\frac{\partial c_{1 k}}{\partial t}=\frac{\partial}{\partial z}\left(K_{z z} \frac{\partial c_{1 k}}{\partial z}\right)+M_{2 k}\left(c_{1 k}, c_{2 k}, \ldots, c_{n k}, T, \mathrm{RH}\right) \\
i=1,2, \ldots, n, \quad k=1,2, \ldots, m
\end{gathered}
$$

where $c_{2 k}$ represents the concentration of species $i$ of size $k$ (if applicable), $K_{z z}$ is the turbulent eddy diffusivity in the vertical direction $z, M_{z k}$ represents the net rate of gain of each species due to chemical reaction or possibly condensation, which is generally a function of the species concentrations, temperature $T$, and relative humidity RH.

Specifically, in the absence of heterogeneous atmospheric chemistry that will occur if a fog exists, the equation for aerosol species $i$ of size $k$ takes the following form:

$$
\begin{gathered}
\frac{\partial c_{\imath k}}{\partial t}=\frac{\partial}{\partial z}\left(K_{z z} \frac{\partial c_{\imath k}}{\partial z}\right)+L_{\imath k}(\mathbf{C}, T, \mathrm{RH}) \\
i=1,2, \ldots, n, \quad k=1,2, \ldots, m
\end{gathered}
$$

with initial conditions

$$
c_{i k}(z, 0)=c_{i k}^{o}(z), \quad t=0
$$

and boundary conditions

$$
\begin{gathered}
\left(K_{z z} \frac{\partial c_{\imath k}}{\partial z}\right)=0, \quad z=H \\
{\left[v_{p}^{k} c_{\imath k}-K_{z z} \frac{\partial c_{\imath k}}{\partial z}\right]=E_{i k}, \quad z=0}
\end{gathered}
$$

In this equation, $L_{\imath k}(\mathbf{C}, T, \mathrm{RH})$ is the rate of gain or loss of the aerosol material due to the movement between the gas and the aerosol phase by diffusion, which is a function of the aerosol species concentrations and gas phase concentrations, denoted by $\mathbf{C}$. Initial species concentrations are denoted by $c_{\imath k}^{o}(z)$, and $H$ is the height of the air column. The particle depo- 
sition velocity $v_{p}^{k}$ is dependent on meteorology, surface roughness, and particle size, and the $E_{i k}$ are size- and chemically specified direct emissions from primary particle sources. Coagulation of particles is neglected for the case of the relatively dilute atmospheric systems of interest to regional air pollution problems.

For gas phase species $i$, equation (1) takes the form

$$
\begin{aligned}
\frac{\partial c_{\imath}}{\partial t}= & \frac{\partial}{\partial z}\left(K_{z z} \frac{\partial c_{i}}{\partial z}\right)+R_{\imath}\left(c_{1}, c_{2}, \ldots, c_{n}, T\right) \\
& -\sum_{k} L_{i k}(\mathbf{C}, T, \mathrm{RH}) ; \quad i=1,2, \ldots, n
\end{aligned}
$$

with initial conditions in addition to equation (3)

$$
c_{\imath}(z, 0)=c_{\imath}^{o}(z), \quad t=0
$$

and boundary conditions in addition to equations (4) and (5).

$$
\begin{gathered}
\left(K_{z z} \frac{\partial c_{\imath}}{\partial z}\right)=0, \quad z=H \\
{\left[v_{g}^{i} c_{\imath}-K_{z z} \frac{\partial c_{\imath}}{\partial z}\right]=E_{\imath}, \quad z=0}
\end{gathered}
$$

$R_{2}\left(c_{1}, c_{2}, \ldots, c_{n}, T\right)$ in equation (6) represents the rate of production or loss of species $i$ at temperature $T$ due to gas phase chemical reactions. $L_{2 k}(\mathbf{C}, T, \mathrm{RH})$ represents the movement of material between the gas and the aerosol phase, as defined previously. Initial gas phase species concentrations are denoted by $c_{i}^{o}(z), H$ is the height of the air column, $v_{g}^{2}$ is the deposition velocity for gaseous species $i$, and $E_{\imath}$ represents direct emissions of species $i$.

A light-scattering module is applied to calculate the light extinction coefficient. The atmospheric light extinction coefficient can be expressed as the sum of four contributions.

$$
b_{\text {ext }}=b_{s p}+b_{a p}+b_{s g}+b_{a g}
$$

The extinction coefficient is the sum of the components due to light scattering by particles $b_{s p}$, light absorption by particles $b_{a p}$, scattering of light by gases $b_{s g}$, also known as Rayleigh scattering when the gas is air, and light absorption by gases $b_{a g}$. Light scattering and absorption by particles is calculated from Mie theory [van de Hulst, 1957].

$$
b_{s p, s p+a p}=\int \frac{\pi \mathrm{D}_{p}^{2}}{4} Q\left(m, \lambda, \mathrm{D}_{p}\right) n\left(\mathrm{D}_{p}\right) d \mathrm{D}_{p}
$$

The light scattering (plus absorption) coefficient is a function of the scattering (plus absorption) efficiency of a particle $Q$ with refractive index $m$, particle diameter $\mathrm{D}_{p}$, as a function of the wavelength of light $\lambda$, and the particle number distribution $n\left(D_{p}\right)$. The scattering (plus absorption) efficiency is calculated from Mie theory for each diameter interval of the aerosol particle size distribution. Then $b_{s p}$ (and $b_{s p+a p}$ ) are calculated by integrating the product of the scattering (+ absorption) efficiency factors for particles of each size, parti- cle cross-sectional area, and the number of such particles per unit air volume over the diameter range represented by the aerosol size distribution. Light absorption by $\mathrm{NO}_{2}$ gas is calculated according to the wavelengthdependent absorption coefficients reported by Hodkinson [1966]. Scattering by gases is calculated as Rayleigh scattering, with $b_{s g}=1.5 \times 10^{-5} \mathrm{~m}^{-1}$ at sea level at a wavelength of $550 \mathrm{~nm}$, and $b_{s g}$ varying with wavelength as $\lambda^{-4}$ [Penndorf, 1957]. These calculation procedures are described in detail by Larson et al. [1988]. The result provides values of the atmospheric light extinction coefficient as a function of wavelength that can be used to estimate visual range via Koschmieder's formula. The extinction coefficient values also can be used to drive a model that generates synthetic photographs of the appearance of the location occupied by the air parcel [Eldering et al., 1993].

\section{Emissions Model}

Emissions information is required for gas phase and particle phase species. The emissions model developed for use with this modeling system assumes that external input data are supplied on the spatial and temporal distribution of the emissions of total suspended particulate matter mass (but not size or chemical composition) along with emissions of $\mathrm{SO}_{2}, \mathrm{NO}, \mathrm{NO}_{2}, \mathrm{NH}_{3}, \mathrm{CO}$, and total nonmethane organic gases. These external input data on total particle mass and gaseous pollutant emissions can come from emission inventories such as those maintained by the State of California that provide hourly time resolution for the typical operations of specific industries and weekday traffic densities. Continuous stack emission monitors are in use at hundreds of locations in California, for example, and thus routine emission inventories can be supplemented by dayspecific records of the actual operations of major point sources such as power plants and petroleum refineries.

The primary particulate matter mass emissions supplied from the emission inventory are subdivided within the model to create primary seed particles of specified size and chemical composition released from each source. This primary particle generation system is based largely on source tests conducted by our research group for use in building this emissions model [Hildemann et al., 1989, 1991a, b]. The mass emission rate, size distribution, and chemical composition of fine aerosol emissions have been measured from catalystequipped automobiles, noncatalyst automobiles, diesel engines, distillate oil-fired boilers, fireplace combustion of wood, meat charbroiling, and meat frying. In the case of natural gas appliances the mass emission rate and chemical composition were measured using the dilution sampling system of Hildemann et al. [1991a], while high-resolution size distribution data for this source are taken from the work of $L i$ and Hopke [1993]. The major fugitive dust source in cities is paved road dust. Its chemical composition was determined by grab sampling, followed by resuspension and collection on filters located downstream of cyclone separators, followed by chemical analysis as before [Hildemann et al., 1991a]. 
Soil dust chemical composition (e.g., from unpaved roads) is as reported by Houck et al. [1989]. The relative proportions of road dust and soil dust in sizes smaller than $10 \mu \mathrm{m}$, smaller than $2.5 \mu \mathrm{m}$, and smaller than $1.0 \mu \mathrm{m}$ are taken from measurements by Houck et al. [1989]. The detailed size distribution of the paved-road dust as well as all other crustal source emissions in sizes below $2.5 \mu \mathrm{m}$ is taken as having a shape proportional to the impactor measurements of fine atmospheric soil dust reported for Claremont, California by Zhang et al. [1993]. The size distribution of the emissions of the larger road dust and soil dust particles in the range from $2.5 \mu \mathrm{m}$ to $10 \mu \mathrm{m}$ is taken as having the same shape as the coarse airborne particle size distributions measured in central Los Angeles by C. Christoforou (personal communication, 1993). Of course, no emissions model can dynamically track all of the short-term fluctuations in source emissions that occur in actual operations. Instead, the purpose here is to try to represent the average size distributions and chemical composition of the emissions from specific critical source types. Toward that end, the source profiles are averaged over multiple-source tests whenever possible: a fleet of six noncatalyst autos, seven catalyst-equipped autos, and two diesel trucks were tested over entire driving cycles on chassis dynamometers; several types of wood combustion were examined, and multiple tests were conducted on oil-fired boilers, natural gas-fired appliances, and meat cooking operations. Still, size-distributed and chemically distributed emission data are rare at present. As the number of source tests increase, it will become possible to better describe average emissions and to expand the range of conditions that can be represented.

Key source-specific primary particle size distributions used within the model are plotted in Figure 1 at a resolution of five particle size intervals per decade in the particle size range from $0.01-\mu \mathrm{m}$ to $10.0-\mu \mathrm{m}$ particle diameter. Higher size resolution is easily attained if desired because the underlying inverted size distributions have been published previously. The chemical composition of all particles from the same source is taken to be identical within the size range represented by a single filter-based determination of chemical composition, but chemical composition varies from one source to another. The sources shown in Figure 1, plus those very similar sources that can be represented by the same profiles, account for $90 \%$ of the primary seed particle mass inserted into the southern California atmosphere. For the remaining minor sources that lack high-resolution submicron size distribution data, gross approximations to their size distribution can be obtained from source profile libraries that give mass fractions in size intervals less than $1-\mu \mathrm{m}, 2.5-\mu \mathrm{m}$, and $10-\mu \mathrm{m}$ particle diameter [Cooper et al., 1989; Houck et al., 1989; Taback et al., 1979; P. D. Allen, personal communication, 1992].

The emissions of all major ionic species $\left(\mathrm{NH}_{4}^{+}, \mathrm{Na}^{+}\right.$, $\left.\mathrm{SO}_{4}^{-}, \mathrm{NO}_{3}^{-}, \mathrm{Cl}^{-}\right)$plus organic compounds, elemental carbon, and crustal (i.e., soillike) material are tracked separately in the emissions that enter the model. Trace metal-rich industrial process materials are tracked as a single lumped chemical class, but individual trace metals are not tracked separately as they compose only a small fraction of the total mass. The air quality model uses a number of discrete particle sizes, $k$, with diameters $d_{k}$, that initially are specified by the user but that grow as the aerosol evolves over time. The particulate matter emissions information is input as an increment to the particle number count and chemical composition for each particle size at each time step by sampling from the underlying size distribution of the emissions from each source at the then current size of the particles of class $k$. In the model application that follows, the aerosol will be represented as if it is an internal mixture (all ambient particles of the same size have the same chemical composition), but the model is clearly capable of separately tracking particles from different sources with different compositions and ages since release; it is a matter of more computer time and memory.

Organic vapor profiles that specify the detailed chemical composition of the effluent from major emission source types, including catalyst and noncatalyst equipped gasoline-powered motor vehicles, diesel vehicles, solvent evaporation, and surface coating applications, have been assembled recently by our research group [Harley et al., 1992]. These organics species profiles are used to map the total vapor phase organics emissions into the emissions of over 400 specific organic compounds. This improved chemical resolution for the vapor phase organics is important for two reasons. First, secondary organic aerosol formation is driven by some organic vapor phase species but not others; a detailed knowledge of precursor composition and concentrations is required. Second, the composition of the organics influences the production of oxidants (e.g., $\mathrm{O}_{3}, \mathrm{H}_{2} \mathrm{O}_{2}$ ) that are important to heterogeneous sulfate formation in clouds and in fogs.

\section{Advection}

Primary particles and gaseous pollutants specified by the emissions model are injected into a vertical stack of five computational cells that represent an air parcel that is advected across the air basin by the observed winds. The horizontal motion of the air parcel is described by trajectories calculated from wind fields that are generated by interpolation of meteorological observations by the method of Goodin et al. [1979]. Vertical transport and diffusion within the stack of computational cells that constitutes the air parcel is described by Russell et al. [1983] and Russell and Cass [1986].

\section{Gas Phase Chemical Kinetics}

The chemical mechanism used to model the gas phase chemical reactions is based on the formulation of Carter [1990] with extensions to track condensible organic gases that may form secondary organic aerosols [Pandis et al., 1992a]. The extended mechanism includes 100 chemical species and 195 reactions, including reactions leading to nitric acid and sulfuric acid formation in the gas phase. The numerical solver for the gas phase chemistry uses the approach of Young and Boris [1977] as implemented 

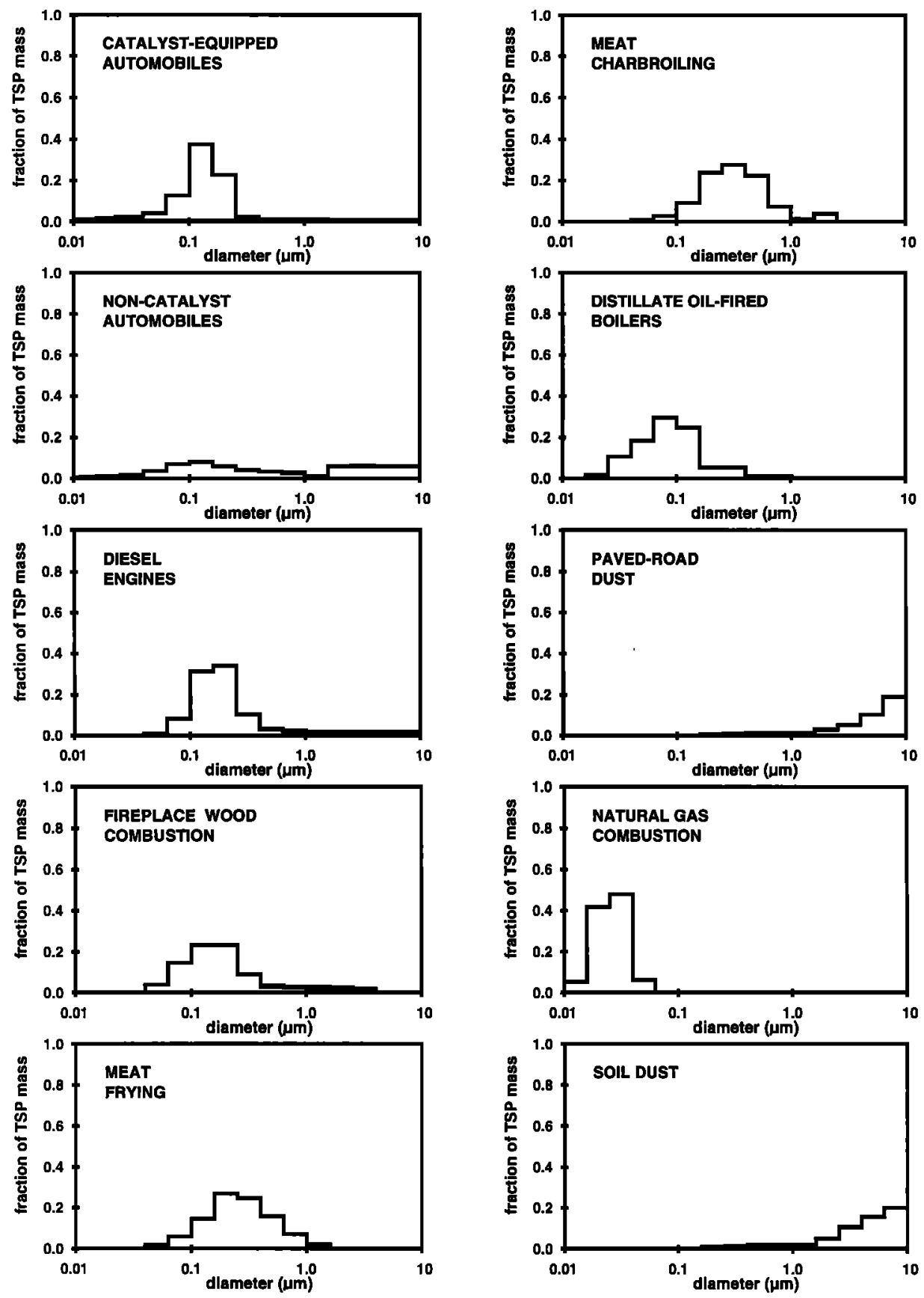

Figure 1. Source-specific primary particle size distributions. The particle diameter range between 0.01 and $10 \mu \mathrm{m}$ is divided into 15 equally spaced intervals on a logarithmic scale, and the fraction of total particulate mass emissions (TSP) falling into each of these size bins is shown. For material, such as soil dust, that is emitted in part in particles greater than $10 \mu \mathrm{m}$ in diameter, the fraction emitted in particles less then $10 \mu \mathrm{m}$ in diameter will not sum to 1.0 .

by previous versions of the CIT air shed model [McRae et al., 1982].

\section{Solar Radiation Fields}

Earlier versions of the present trajectory model computed photolysis rate constants from an actinic flux model for clear sky conditions based on solar position and time of day [McRae et al., 1982; Russell et al., 1983; Russell and Cass, 1986]. As discussed by Harley et al. [1993b], photolysis rates may differ from those predicted from actinic flux models due to pollutant concentrations and cloud cover. The present trajectory model accepts a temporally varying ground level photolysis scaling factor field and a regionwide insolation correction factor applied at the upper boundary of the model that can be set based on field measurements of the ultraviolet solar flux. The vertical variation of photolysis rate constants is estimated by linear interpolation between ground level photolysis rates and photolysis rates at the top of the air parcel. The model also accepts a 
total solar radiation scaling factor field which can be used to attenuate the clear sky photolysis rates computed by the model's internal solar simulator according to the reported spatial distribution of the fraction of the sky that is covered by clouds.

\section{Dry Deposition}

The dry deposition of gases is computed using the approach described by McRae et al. [1982] and Russell et al. [1984]. For particles the dry deposition velocity is calculated according to the formulation of Slinn and Slinn [1980] for dry particles and Seinfeld [1986]. The deposition velocity for particles $v_{p}^{k}$ is defined as

$$
v_{p}^{k}=\frac{1}{r_{C}^{k}+r_{D}^{k}+r_{C}^{k} r_{D}^{k} v_{s}^{k}\left(a_{d}^{k}\right)}+v_{s}^{k}\left(a_{d}^{k}\right)
$$

with

$$
\begin{gathered}
\left(r_{C}^{k}\right)^{-1}=\frac{u_{*}^{2}}{\bar{u}} \\
\left(r_{D}^{k}\right)^{-1}=u_{*}\left[\left(S c^{k}\right)^{-2 / 3}+10^{-3 / S t^{k}}\right]
\end{gathered}
$$

where $r_{C}^{k}$ is the resistance in the constant flux layer or the aerodynamic resistance, and $r_{D}^{k}$ is the resistance in the deposition layer immediately adjacent to the ground, also called the surface layer resistance. $S c^{k}$ is the Schmidt number for particles of size $k$ (kinematic viscosity of the air divided by the Brownian diffusivity of particles in air), $S t^{k}$ is the Stokes number for particles of size $k$, and $v_{s}^{k}$ is the gravitational settling velocity of particles with aerodynamic diameter $a_{d}^{k}$. The mean wind velocity is $\bar{u}$, and $u_{*}$ is the friction velocity. The particle deposition velocity for particles greater than about $1 \mu \mathrm{m}$ in diameter is dominated by gravitational settling and inertial impaction. For smaller particles, Brownian diffusion is the dominant process leading to particle deposition.

\section{Diffusion of Gases to and From Particles}

To account for the movement of inorganic gases to and from particles, the AIM computer code of Wexler and Seinfeld [1991] is employed. In this calculation scheme the movement of mass is determined by the physical properties (diffusivity), temperature, number of particles present, the ambient gas phase concentrations of species and the equilibrium gas phase species concentrations at the particle surface. To calculate the surface equilibrium concentrations, the aerosol phase state and composition is estimated by assuming that more than one phase is present in the aerosol and that the phases are in thermodynamic equilibrium with the Gibbs free energy at a global minimum. The following equation is then solved for each chemical species present in particles of size $k$.

$$
\frac{d P_{i k}}{d t}=\frac{4 \pi N_{k} D_{\imath} r_{k}}{\beta+1}\left(c_{\imath}^{\infty}-c_{\imath}^{e}\right)
$$

In this equation, $P_{i k}$ is the concentration of the $i$ th chemical species present in particles of size $k, N_{k}$ represents the number concentration of particles of size $k$,
$D_{\imath}$ is the gas phase molecular diffusivity of species $i$, and $r_{k}$ is the particle radius; $\beta$ accounts for imperfect accommodation; $\beta=D_{i} / \alpha_{i} s_{i} r_{k}$, where $\alpha_{2}$ is the accommodation coefficient of species $i$ and $s_{i}$ is the molecular velocity of species $i$. The ambient gas phase concentration and the equilibrium gas phase concentration of species $i$ at the particle surface are represented by $c_{\imath}^{\infty}$ and $c_{\imath}^{e}$, respectively. Equation (15) is written for each condensible chemical species in each of the $k$ particle sizes, and the equations are solved simultaneously. The species fluxes resulting from this solution step then are used to represent $L_{\imath k}$ in expressions (2) and (6). After solving this set of equations, the diameter of each particle of size $k$ is recalculated to account for the material added or lost, and the gas phase species concentrations are updated to reflect material gained or lost by the particles.

For condensible organic gases a parallel formulation is used. The diffusional growth equation is solved for a number of condensible organic aerosol species. Because the exact saturation vapor pressure of each of the many low vapor pressure secondary organic reaction products is not known, the secondary organic aerosol material computed from the gas phase kinetic mechanism is assumed to be transferred entirely to the particle phase. Thus an upper limit on the secondary organic aerosol concentration is calculated.

The work of Heisler and Friedlander [1977] discusses experiments performed to determine the aerosol growth laws governing secondary aerosols in photochemical smog. In this work, Heisler and Friedlander estimated a critical size or Kelvin cutoff diameter, below which growth did not occur due to the vapor pressure-raising effect of particle surface curvature. From experiments conducted in a Teflon bag smog chamber, they found cutoff diameters of 0.1 to $0.3 \mu \mathrm{m}$ for secondary organic aerosols produced by reaction from cyclohexene and 1,7-octadiene. When fitting their growth law to observed ambient data, they used a model with two condensible species, the components having critical diameters of 0.055 and $0.24 \mu \mathrm{m}$. Mozurkewich [1993] has examined the effect of particle size on ammonium nitrate aerosols and reports that the Kelvin effect has an important effect on the dissociation of $\mathrm{NH}_{4} \mathrm{NO}_{3}$ at particle sizes less than $0.1 \mu \mathrm{m}$. For the present work, a critical diameter of $0.1 \mu \mathrm{m}$ will be used, below which no growth by condensation will be allowed to occur.

\section{Fog Calculations}

Previous investigators have explained elevated sulfate concentrations in urban aerosols with models that simulate the aqueous phase chemistry in fogs, allowing for heterogeneous sulfate formation [Pandis et al., 1992b]. More recent work [Meng and Seinfeld, 1994] has shown that droplet size particles in a size-distributed aerosol can be accounted for by the activation of fine aerosol particles to form fog or cloud drops, followed by aqueous phase chemistry, and fog evaporation. In the present study, an approximate model of fog processes that takes into account size-specific aerosol chemistry 
and gas phase pollutant concentrations is used. When a trajectory enters a fog, particles are activated according to the predictions of the Köhler equation [Pruppacher and Klett, 1978]. Particles that are activated at the assumed supersaturation achieve the diameter of a fog droplet by water addition from the vapor phase. Gases move into the aqueous phase according to Henry's law, subject to mass conservation constraints. Oxidation of dissolved S(IV) species to form sulfate (S(VI)) occurs within the fog droplets by aqueous reactions involving $\mathrm{H}_{2} \mathrm{O}_{2}$ and $\mathrm{O}_{3}$ and oxidation catalyzed by $\mathrm{Fe}^{3+}$ and $\mathrm{Mn}^{2+}$. These reactions are thought to be the most significant $\mathrm{SO}_{2}$ oxidation reactions in the $p \mathrm{H}$ range of 2-8 [see Pandis and Seinfeld, 1989]. The reactions shown in Table 1 are propagated by dissolved S(IV) species and by oxidant concentrations determined from the gas phase photochemical trajectory model, with fog $p \mathrm{H}$ values and catalyst levels determined by field experimental observations. The particles that have not been activated continue to interact with the gas phase as described previously. When the air parcel trajectory moves out of the fog, the water dissipates and the particles achieve new diameters determined by the drier, nonvolatile remaining components now contained in the former fog droplet (e.g., sulfates, sodium compounds, carbonaceous material, and crustal materials) plus any nitrate, chloride, and ammonium that would remain in equilibrium with the new gas phase conditions.

\section{Solution Technique}

To create a tractable model, operator splitting was employed in these calculations, with the vertical transport and chemical reactions of the gas phase species remaining linked in the first calculation step. Vertical diffusion of aerosol species is calculated next and then the transport between the vapor and the particle phase, followed by fog chemistry when applicable.

\section{Light Scattering}

The next step in this visibility model is the calculation of light scattering and absorption by aerosol particles and gases. The number of particles of each size is known from the aerosol model results, and the refractive index of particles of each size is estimated from the predicted aerosol chemical composition [Stelson, 1990; Sloane, 1984b]. The particle light-scattering coefficient $b_{s p}$ and particle light absorption coefficient $b_{a p}$ next are calculated by integrating over the size distribution of the aerosol as in equation (11). Light scattering by air molecules is computed according to the data of Penndorf [1957]. The $\mathrm{NO}_{2}$ concentration predicted by the model is used to compute light absorption by gases [Hodkinson, 1966]. The computed light scattering and absorption by particles and gases is then summed in order to arrive at the total light extinction coefficient as a function of wavelength.

The particle light extinction coefficient is calculated from Mie theory, and sky color and skylight intensity can be calculated from the solution of the radiative transfer equation, as described by Sloane [1988] and as tested by Eldering et al. [1993]. An estimate of visual range can be calculated by applying Koschmieder's formula [Middleton, 1952] to the computed total extinction coefficient. This information also can be used to drive previously described image processing-based visibility models [Eldering et al., 1993] that can produce synthetic color photographs of the appearance of the surrounding landscape as it would be seen from inside the air parcel in those cases where the visual range $L_{v}$ is comparable to the dimensions of the air parcels tracked by a trajectory model (i.e., when $L_{v}$ is less than or equal to several kilometers).

\section{Model Application}

The strategy employed here for model evaluation generally follows the pattern set by previous gas phase model evaluation studies. First, many components of the model have been tested separately. These include the underlying trajectory model and the ammonia emissions inventory [Russell and Cass, 1986], the aerosol thermodynamics module [Wexler and Seinfeld, 1991], improvements to the gas phase organics inventory [Harley et al., 1992], and the ability to model ozone, $\mathrm{NO}_{2}$, individual vapor phase organic compounds, and secondary organic aerosol concentrations [Harley et al., 1993a, b; Harley and Cass, 1995; Pandis et al., 1992a]. While maintaining these previously tested features of the model, data sets are sought that permit examination of the novel aerosol and visibility-related processes described within the present model. Air parcel trajectories ending at a location where aerosol size distributions,

Table 1. Sulfur Species Aqueous Oxidation Rate Expressions

\begin{tabular}{lll}
\hline Oxidant & \multicolumn{1}{c}{ Rate Expression $^{a}$} & \multicolumn{1}{c}{ Rate Constant } \\
\hline $\mathrm{H}_{2} \mathrm{O}_{2}$ & $\mathrm{R}=\mathrm{k}\left[\mathrm{H}^{+}\right]\left[\mathrm{HSO}_{3}^{-}\right]\left[\mathrm{H}_{2} \mathrm{O}_{2(a q)}\right] /\left(1+\mathrm{K}\left[\mathrm{H}^{+}\right]\right)$ & $\mathrm{k}=7.510^{7} \mathrm{M}^{-2} \mathrm{~s}^{-1}$ at $298 \mathrm{~K}$ \\
& & $\mathrm{~K}=13 \mathrm{M}^{-1}$ \\
$\mathrm{O}_{2}$ & $\mathrm{R}=\mathrm{k}[\mathrm{Fe}(\mathrm{III})]\left[\mathrm{SO}_{3}^{2-}\right]$ & $\mathrm{k}=1.210^{6} \mathrm{M}^{-1} \mathrm{~s}^{-1}$ at $298 \mathrm{~K}, p \mathrm{H} \leq 5$ \\
$\mathrm{O}_{2}$ & $\mathrm{R}=\mathrm{k}_{1}[\mathrm{Mn}(\mathrm{II})]\left[\mathrm{HSO}_{3}^{-}\right]$ & $\mathrm{k}_{1}=3.410^{3} \mathrm{M}^{-1} \mathrm{~s}^{-1}$ at $298 \mathrm{~K}$ \\
$\mathrm{O}_{3}$ & $\mathrm{R}=\left(\mathrm{k}_{0}\left[\mathrm{SO}_{2} \cdot \mathrm{H}_{2} \mathrm{O}\right]+\mathrm{k}_{1}\left[\mathrm{HSO}_{3}^{-}\right]+\mathrm{k}_{2}\left[\mathrm{SO}_{3}^{2-}\right]\right)\left[\mathrm{O}_{3(a q)}\right]$ & $\mathrm{k}_{0}=2.410^{4} \mathrm{M}^{-1} \mathrm{~s}^{-1}$ at $298 \mathrm{~K}$ \\
& & $\mathrm{k}_{1}=3.710^{5} \mathrm{M}^{-1} \mathrm{~s}^{-1}$ \\
& & $\mathrm{k}_{2}=1.510^{9} \mathrm{M}^{-1} \mathrm{~s}^{-1}$ \\
\hline
\end{tabular}

${ }^{a}$ All reaction rates from Hoffmann and Calvert (1985). 
chemical composition and light scattering and absorption have been measured will be examined through the model. Conventional statistical measures of model performance, including comparisons of means, biases, and standard errors between predictions and observations will be prepared for most important model parameters, and visual assessment of model performance will be assisted through presentation of time series and aerosol size distribution graphs. In those cases where model input data present major uncertainties, analyses will be pursued to determine model sensitivity to altered input data values.

As part of the 1987 Southern California Air Quality Study (SCAQS), a large cooperative air quality measurement program was carried out in the South Coast Air Basin of California to gather information to be used in the design and evaluation of air quality models [Lawson, 1990]. Detailed measurements of gas and particle phase pollutant concentrations were made continuously over short averaging times during 11 intensive sampling days in the summer and 6 days in the fall of 1987. The gas phase measurements included $\mathrm{O}_{3}$, $\mathrm{NO}, \mathrm{NO}_{x}, \mathrm{SO}_{2}, \mathrm{NH}_{3}, \mathrm{HNO}_{3}$, and detailed speciation of the volatile organic compounds present. Particulate matter was collected at nine sampling sites in two particle size ranges, those particles having diameters less than $2.5 \mu \mathrm{m}$ (PM2.5) and particles with diameters less than $10 \mu \mathrm{m}$ (PM10) using the SCAQS sampler designed by Fitz et al. [1989]. Filter samples were collected over consecutive 4- to 7-hour sampling periods and were analyzed for sulfate, nitrate, ammonium ion, chloride, sodium, organic carbon, elemental carbon, and 29 other elements including $\mathrm{Fe}, \mathrm{Mn}$, and $\mathrm{V}$. In addition, ambient aerosol size distribution and particle light-scattering coefficient measurements were made using electrical aerosol analyzers (TSI model 3030) and optical particle counters (Particle Measuring Systems LAS-X) at five intensive monitoring sites [Eldering et al., 1994]. Continuous light-scattering measurements were made at these sites using integrating nephelometers. Of the days represented by the SCAQS database, the episode that occurred on August 27-28, 1987, was selected for the present visibility model evaluation effort. August 28 is the most polluted of the summer intensive sampling days and also experienced visibility that was among the lowest measured during the SCAQS sampling days. The August 27-28 SCAQS database also contains detailed measurements of the size distribution of the sulfates, nitrates, organic carbon, elemental carbon, and soil dust taken at Claremont, California, using cascade impactors by John et al. [1989] and by Zhang et al. [1993]. Prior analysis of the chemical composition of filter samples and particle size distribution measurements made at Claremont on these days by electrical aerosol analyzers and optical particle counters have shown that data are available for model verification that are in reasonable agreement with the observed level of light scattering [Eldering et al., 1994]. For these reasons, air parcel trajectories terminating at Claremont will be studied here.
The meteorological data necessary to exercise the trajectory model for the August 27-28 SCAQS period were assembled by Harley et al. [1993a], as part of an earlier study of photochemical smog formation. The input data required include hourly temperature, humidity, surface winds, mixing depths, total solar radiation, and ultraviolet radiation scaling factor fields. With the exception of mixing depths, these data were assembled from ground-based measurements followed by spatial interpolation using the objective analysis techniques of Goodin et al. [1979]. Mixing depths were determined from potential temperature analysis of SCAQS upper air soundings.

Air parcels were tracked over a period of two days, starting over the ocean and terminating at Claremont. Trajectories were computed using gridded hourly wind field data prepared by the methods of Goodin et al. [1979] by specifying the trajectory endpoint at Claremont and time of arrival and integrating backward in time. For this modeling work, 24 trajectories were used, one arriving at Claremont each hour of August 28. An example of one such trajectory is shown in Figure 2. These are the same trajectories as studied by Pandis et al. [1992a, 1993], but the emissions model, the representation of the aerosol size distribution as a discrete distribution of Lagrangian particles, the chemistry model, the fog chemistry model, the dry deposition model, and the light-scattering code, are different. As a result, the model outcome is different.

\section{Particulate Emissions Inventory}

Day-specific emission inventories for August 27 and 28, 1987, provided by the California Air Resources Board (ARB) (Wagner and Allen, personal communication, 1990) provide the starting point for our emission processing procedures. This inventory includes spatially resolved total particle mass emission rates for 455 separate source types present in southern California. The largest contributors to these mass emissions, including motor vehicle exhaust and paved-road dust, were examined carefully and revised.

In the ARB inventory, on-road vehicle emissions, including catalyst-equipped autos and trucks, noncatalyst gasoline-powered vehicles, and diesel vehicles, are grouped together. To permit the use of more specific information on mass emission rates, particle chemical composition, and particle size, these categories were separated for the current work and new estimates of the total mass emissions from on-road motor vehicles were constructed. The number of vehicle kilometers traveled within the South Coast Air Basin each day by vehicles of each type for an average day in 1987 were obtained from the 1991 revision of the South Coast Air Quality Management District (SCAQMD) air quality management plan [Chang et al., 1991]. Particulate matter emission rates in grams per kilometer travelled were taken from those reported by Hildemann et al. [1991a, b] and Gray [1986]. Mass emission estimates were computed for catalyst-equipped light-duty autos, catalystequipped light-duty trucks, catalyst-equipped medium- 

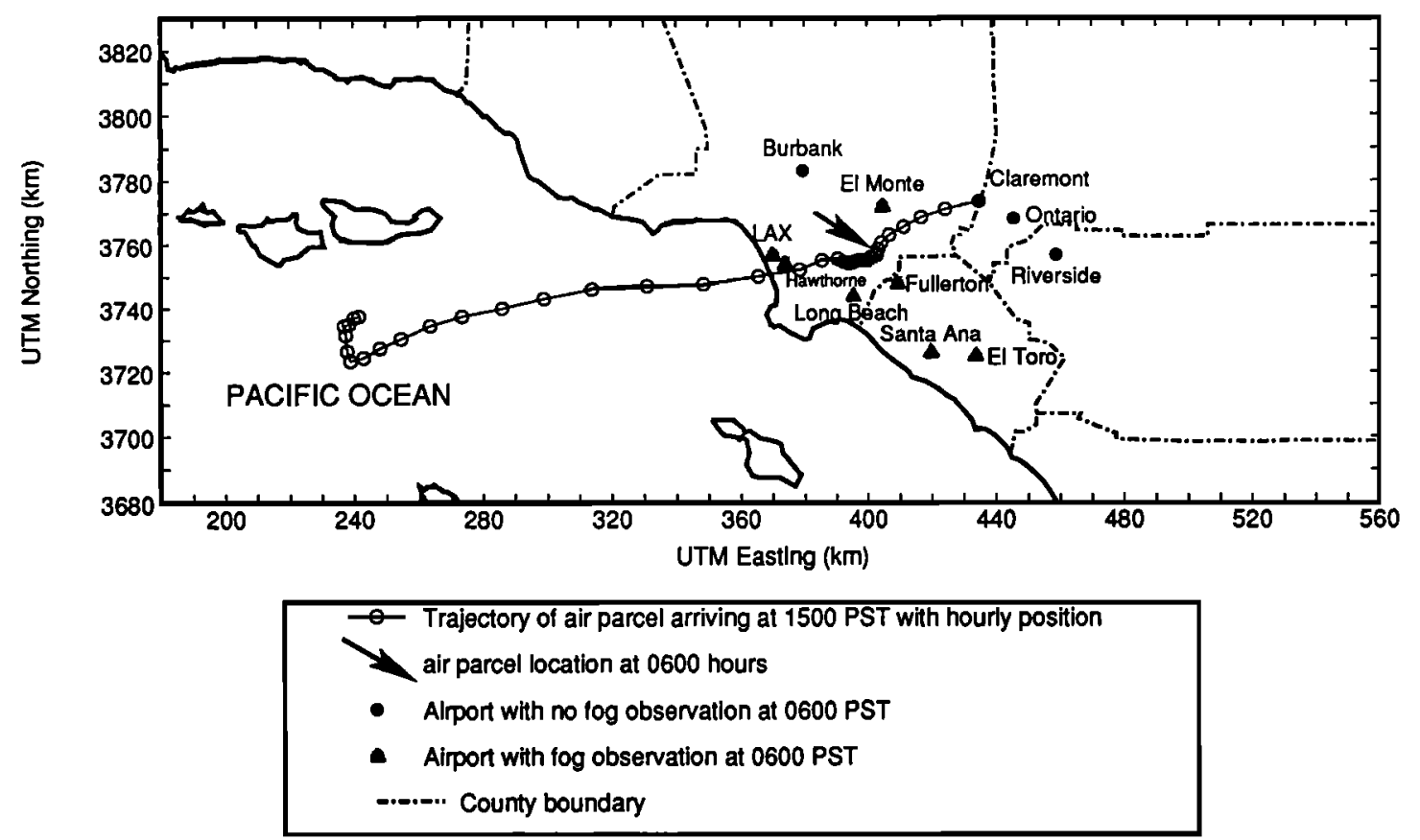

Figure 2. Path followed by the air parcel arriving at Claremont at 1500 PST on August 28, 1987. The circles along the trajectory path mark the location at each hour. The position of the air parcel at 0600 PST is shown by an arrow and the air parcel is seen to be surrounded by airports reporting fog at that time.

duty trucks, catalyst-equipped heavy-duty trucks, motorcycles, noncatalyst light-duty autos, noncatalyst lightduty trucks, noncatalyst medium-duty trucks, noncatalyst heavy-duty trucks, diesel light-duty automobiles, diesel light-duty trucks, diesel heavy-duty trucks, diesel urban buses, and tire wear. The ARB motor vehicle emissions inventory was used only to provide the relative spatial and temporal distribution of the new estimates for total mass emission rates from on-road vehicles.

The ARB estimates for total mass emissions of pavedroad dust and dust from construction and demolition activities were scaled to match more recent information from the South Coast Air Quality Management District and the Midwest Research Institute [Englehart and Muleski, 1991]. This resulted in a decrease in total mass emissions from both of these sources. Particulate mass emission rates from the remaining sources are as specified by the ARB.

The primary particle mass emission rate data next were passed to the emissions processing model created for use in the present study. The detailed size distribution data of Figure 1 and the corresponding chemical composition data of Hildemann [1991a] were used to cast the emissions from the major sources that can be represented by those profiles into equivalent particle number counts and chemical composition in 15 discrete particle sizes from $0.01-\mu \mathrm{m}$ to $10-\mu \mathrm{m}$ particle diameter. The initial particle sizes are equally spaced on a $\log$ diameter scale with the initial diameters at the $\log$ center of each division. Of the particulate matter mass emissions, $90 \%$ are represented by the size composition profiles of Figure 1.
For industrial sources not represented in Figure 1, - specific chemical speciation information was sought from the South Coast Air Quality Management District PM10 Source Composition Library [Cooper et al., 1989] which represents source tests within the study area. Nineteen additional source chemical composition profiles were used to replace the ARB inventory chemical composition information for a number of industrial sources. The data of Cooper et al. [1989] do not provide size distribution data, so the low-resolution particle size data (i.e., particles $\leq 1-\mu \mathrm{m}, 1$ - to $2.5-\mu \mathrm{m}, 2.5$ - to $10-\mu \mathrm{m}$ particle diameter) assigned to similar sources in the ARB inventory were applied to these sources.

For the remaining sources, particle size and chemical composition data furnished by the ARB were used. The original ARB particulate matter emission inventory includes source chemical and size-specific information for four particle size groups: diameters of less the $1 \mu \mathrm{m}$, diameters from 1 to $2.5 \mu \mathrm{m}$, diameters from 2.5 to 10 $\mu \mathrm{m}$, and diameters greater than $10 \mu \mathrm{m}$. The ARB provided 67 particulate matter source profile codes, which use 50 different source chemical composition profiles. Many of the ARB source size and chemical composition descriptions originate from Taback et al. [1979]. Some of the values coded into these profiles by the ARB can be improved with more recent information, or by correcting the coding of the original information. In Taback et al.'s report, the total carbon weight fraction reported represented both volatile organic carbon plus nonvolatile elemental (black) carbon. In many instances in the ARB emission inventory, Taback et al.'s emissions information on the element carbon (i.e., total carbon) was coded as if it were elemental (black) carbon. In 
Table 2. Source-Specific PM10 Emissions for the South Coast Air Basin

\begin{tabular}{lcrr}
\hline \multicolumn{1}{c}{ Source Type } & $\begin{array}{c}\text { PM10, } \\
10^{3} \mathrm{~kg} \mathrm{~d}^{-1}\end{array}$ & $\begin{array}{r}\text { PM2.5, } \\
10^{3} \mathrm{~kg} \mathrm{~d}^{-1}\end{array}$ & $\begin{array}{r}\text { PM1, } \\
10^{3} \mathrm{~kg} \mathrm{~d}^{-1}\end{array}$ \\
\hline Stationary source fuel combustion & 8.61 & 8.56 & 8.50 \\
Waste burning & 0.04 & 0.04 & 0.03 \\
Solvent use & 1.78 & 1.51 & 1.34 \\
Petroleum processing, storage & 2.08 & 1.77 & 1.41 \\
Industrial processes & & & \\
chemical & 0.11 & 0.10 & 0.10 \\
food and agriculture & 24.24 & 24.15 & 23.24 \\
mineral processing & 0.61 & 0.41 & 0.22 \\
metal processing & 0.88 & 0.84 & 0.80 \\
wood and paper & 4.57 & 2.12 & 1.07 \\
other & 0.15 & 0.12 & 0.11 \\
Miscellaneous processes & & & \\
farming operations & 35.74 & 4.77 & 3.59 \\
construction and demolition & 121.68 & 26.63 & 12.29 \\
paved-road dust & 147.13 & 27.47 & 12.67 \\
unpaved-road dust & 47.39 & 10.35 & 4.77 \\
waste disposal & 0.39 & 0.37 & 0.36 \\
natural sources & 65.98 & 19.91 & 9.19 \\
Mobile sources & & & \\
catalyst-equipped vehicles & 3.38 & 3.30 & 3.27 \\
non-catalyst vehicles & 7.86 & 5.64 & 4.77 \\
diesel vehicles & 14.07 & 13.37 & 12.80 \\
off road vehicles & 0.75 & 0.70 & 0.67 \\
trains & 0.61 & 0.58 & 0.55 \\
ships & 2.03 & 1.94 & 1.86 \\
aircraft & 3.09 & 3.07 & 3.05 \\
mobile and utility equipment & 7.65 & 7.13 & 113 \\
Total & 501 & 165 & \\
\hline
\end{tabular}

Day-specific revised inventory for August 27-28, 1987.

most cases the elemental carbon mass emission rates and size distribution data used in our present study come from Hildemann et al. [1991a] or Gray [1986]; but in the cases where an ARB source composition profile is used, a check was made to correct the above mentioned coding error in the ARB database.

A highly aggregated summary of the revised emission inventory for August 27-28, 1987, is given in Tables 2 and 3 and is illustrated by particle size and chemical composition in the lower frame of Figure 3. Figure 3 and Table 3 highlight the large differences between the ARB emissions inventory and our revised primary particle emission inventory. The overall PM10 mass emissions are reduced to $38 \%$ of the rate estimated by the ARB, and fine particle emissions within the revised inventory are $32 \%$ of the ARB-reported mass emissions. Analysis of the difference in PM10 mass emissions for each chemical substance, by source category, between the ARB inventory and the revised inventory highlights the source categories that are responsible for most of the inventory differences. PM10 primary sulfate emissions decrease by $89 \%$ due to a $42 \times 10^{3} \mathrm{~kg} \mathrm{~d}^{-1}$ decrease in primary sulfate emissions from on-road motor vehicles plus a $5 \times 10^{3}$ $\mathrm{kg} \mathrm{d}^{-1}$ decrease in the mass of PM10 primary sulfate emissions from other sources. This is a very important change because the excess primary sulfate emissions in the ARB inventory could have masked an underprediction of secondary sulfate production by the air quality model. (The ARB primary sulfate emissions were incorrect in part because they assigned Taback et al.'s source test of an internal combustion engine burning sewagetreatment plant digester gas to represent the emissions from gasoline-fueled internal combustion engines and engines burning landfill or process gas.) PM10 elemental carbon (EC) emissions decrease by $62 \%$ through a combination of a $12 \times 10^{3} \mathrm{~kg} \mathrm{~d}^{-1}$ decrease in the emissions from on-road vehicles relative to the ARB inventory, a $6.6 \times 10^{3} \mathrm{~kg} \mathrm{~d}^{-1}$ decrease in PM10 EC emissions from paved-road dust, and smaller decreases in PM10 EC emissions from a number of other sources. The excessive elemental carbon emissions present in the original ARB emissions inventory would be particularly damaging to a visibility modeling study due to the high light absorption efficiency of black elemental carbon. Primary organic carbon particle emissions decreased overall by $32 \%$ relative to the ARB inventory, through a combination of increases in some source categories and decreases in others. PM10 organic carbon emitted from the paved-road dust category was reduced by $66 \times 10^{3} \mathrm{~kg} \mathrm{~d}^{-1}$ in the revised inventory when compared to the ARB inventory, while organic compounds emitted from on-road vehicles increased by $14 \times 10^{3} \mathrm{~kg}$ $\mathrm{d}^{-1}$. A change in the chemical composition of emissions from commercial charbroiling and frying increased organics emissions from those sources by $15 \times 10^{3} \mathrm{~kg} \mathrm{~d}^{-1}$ relative to the ARB inventory. 
Table 3. Emissions of Particulate Matter in the South Coast Air Basin

\begin{tabular}{ccc}
\hline & ARB & Revised \\
Species & $10^{3} \mathrm{~kg} \mathrm{~d}^{-1}$ & Inventory $_{1}^{3} \mathrm{~kg} \mathrm{~d}^{-1}$ \\
\hline
\end{tabular}

PM10

$\begin{array}{lcc}\mathrm{Na}^{+} & 2.7 & 1 \\ \mathrm{Cl}^{-} & 15 & 1.6 \\ \mathrm{NH}_{4}^{+} & 0.8 & 0.2 \\ \mathrm{NO}_{3}^{-} & 2.3 & 2 \\ \mathrm{SO}_{4}^{\frac{3}{4}} & 53 & 6 \\ \text { Organic material } & 120 & 81 \\ \text { Elemental carbon (EC) } & 40 & 15 \\ \text { Crustal material } & & 331 \\ \text { Metal-rich industrial } & & 17 \\ \text { Other identified } & 620 & \\ \text { Other unidentified } & 455 & 46 \\ \text { Total } & 1309 & 501\end{array}$

PM2.5

\begin{tabular}{lcc}
$\mathrm{Na}^{+}$ & 0.7 & 0.5 \\
$\mathrm{Cl}^{-}$ & 11 & 1.1 \\
$\mathrm{NH}_{4}^{+}$ & 0.7 & 0.2 \\
$\mathrm{NO}^{-}$ & 1.4 & 1.1 \\
$\mathrm{SO}_{4}^{\frac{3}{4}}$ & 49 & 4 \\
Organic material & 40 & 48 \\
Elemental carbon (EC) & 33 & 13 \\
Crustal material & & 68 \\
Metal-rich industrial & & 16 \\
Other identified & 250 & \\
Other unidentified & 134 & 15 \\
Total & 520 & 167 \\
\hline
\end{tabular}

Day-specific revised inventory for August 27-28, 1987.

\section{Gas Phase Emission Inventory}

Preparation of the gas phase emission inventory for $\mathrm{NO}, \mathrm{NO}_{2}, \mathrm{CO}$, and volatile organic compounds (VOC) begins with the SCAQS day-specific emission files for August 27-28 prepared by the California Air Resources Board (Wagner and Allen, personal communication, 1990). Motor vehicle exhaust measurements made in a highway tunnel during the SCAQS field study [Ingalls, 1989] have shown that the emissions of organic gases and carbon monoxide from motor vehicles in Los Angeles are significantly higher than suggested by the EMFAC7E motor vehicle emissions model used by the ARB to prepare the SCAQS inventory [Pierson et al., 1990; Ingalls, 1989]. Through analysis of the tunnel study data, Harley et al. [1993b] report that the carbon monoxide and organic gas hot exhaust emissions from on-road vehicles should be increased to 3 times the official inventory levels, and this correction has been made in the present study as it has been in previous photochemical modeling studies of the SCAQS smog episodes by Harley et al. [1993a, b]. The revised VOC mass emission inventory next was divided between 414 individual organic species according to the source-specific VOC speciation procedures of Harley et al. [1992] that are built into our emissions model. These VOC species then were lumped into the 28 organic classes required for secondary organic aerosol formation calculations by the procedure of Pandis et al. [1992a].

The 1982 spatially and temporally resolved ammonia emission inventory for the South Coast Air Basin prepared by Gharib and Cass [1984] was used to represent $\mathrm{NH}_{3}$ emissions within the present study. This inventory, including the contributions of the various sources and the resultant spatial distribution of $\mathrm{NH}_{3}$ emissions, has been published previously by Russell and Cass [1986].

\section{Initial Conditions}

Initial conditions for particulate chemical species mass concentrations were specified according to filter-based measurements of aerosol chemistry made using the SCAQS sampler at San Nicolas Island during SCAQS, while the shape of the initial size distribution was estimated from impactor-based, chemically specific size distribution measurements made near the coast by John et al. [1989] at Long Beach, California, during SCAQS. Initial concentrations of the various aerosol chemical species are $3 \mu \mathrm{g} \mathrm{m}^{-3} \mathrm{Cl}^{-}, 2 \mu \mathrm{g} \mathrm{m}^{-3} \mathrm{Na}^{+}, 1 \mu \mathrm{g} \mathrm{m}^{-3} \mathrm{NO}_{3}{ }^{-}$, $1.4 \mu \mathrm{g} \mathrm{m}^{-3} \mathrm{NH}_{4}^{+}, 3 \mu \mathrm{g} \mathrm{m}^{-3} \mathrm{SO}_{4}=, 0.3 \mu \mathrm{g} \mathrm{m}^{-3}$ elemental carbon, and $1 \mu \mathrm{g} \mathrm{m}^{-3}$ organic material. The size distribution of the chemical composition of the initial aerosol inserted into each air parcel over the ocean upwind of the air basin is shown in Figure 4. Initial conditions for the most abundant gaseous air pollutants are $113 \mathrm{ppb} \mathrm{CO}, 5 \mathrm{ppb} \mathrm{NO}, 40 \mathrm{ppb} \mathrm{O}, 11 \mathrm{ppb} \mathrm{MEK}, 3.8$ ppb $\mathrm{HCHO}$, and $3.5 \mathrm{ppb} \mathrm{CH}_{3} \mathrm{CHO}$ based on measurements made at San Nicolas Island and by aircraft flights over the ocean during SCAQS. Gaseous pollutant initial conditions are substantially the same as the upwind boundary conditions used previously for modeling the SCAQS August episode by Harley et al. [1993b] and by Pandis et al. [1992a].

\section{Mapping the Occurrence of Fog}

Virtually all days of record with sulfate concentrations exceeding $25 \mu \mathrm{g} \mathrm{m}^{-3}$ in the Los Angeles area are days where fog is reported at coastal airports [Cass, $1976 ; 1979]$. Examination of the size distribution of the aerosol measured at Claremont during SCAQS [Eldering et al., 1994] shows a very pronounced peak in the size distribution on August 27 and 28 at a particle diameter of approximately $0.7 \mu \mathrm{m}$, a phenomenon generally associated with heterogeneous sulfate formation within liquid water drops [Hering and Friedlander, 1982; McMurry and Wilson, 1983; Meng and Seinfeld, 1994]. Therefore a check was made of the Federal Aviation Administration (FAA) fog observations taken at airports located between Claremont and the coast on August 27 and 28 to see whether or not fog was reported along the path followed by the air parcel trajectories.

This survey revealed at least three fog events of possible importance on the night of August 27-28. Trajectories arriving at Claremont between $0400-1100$ PST on August 28 stagnated overnight very near Claremont. The nearest airport to Claremont is at Ontario, $10 \mathrm{~km}$ to the southeast; fog was reported at Ontario Interna- 

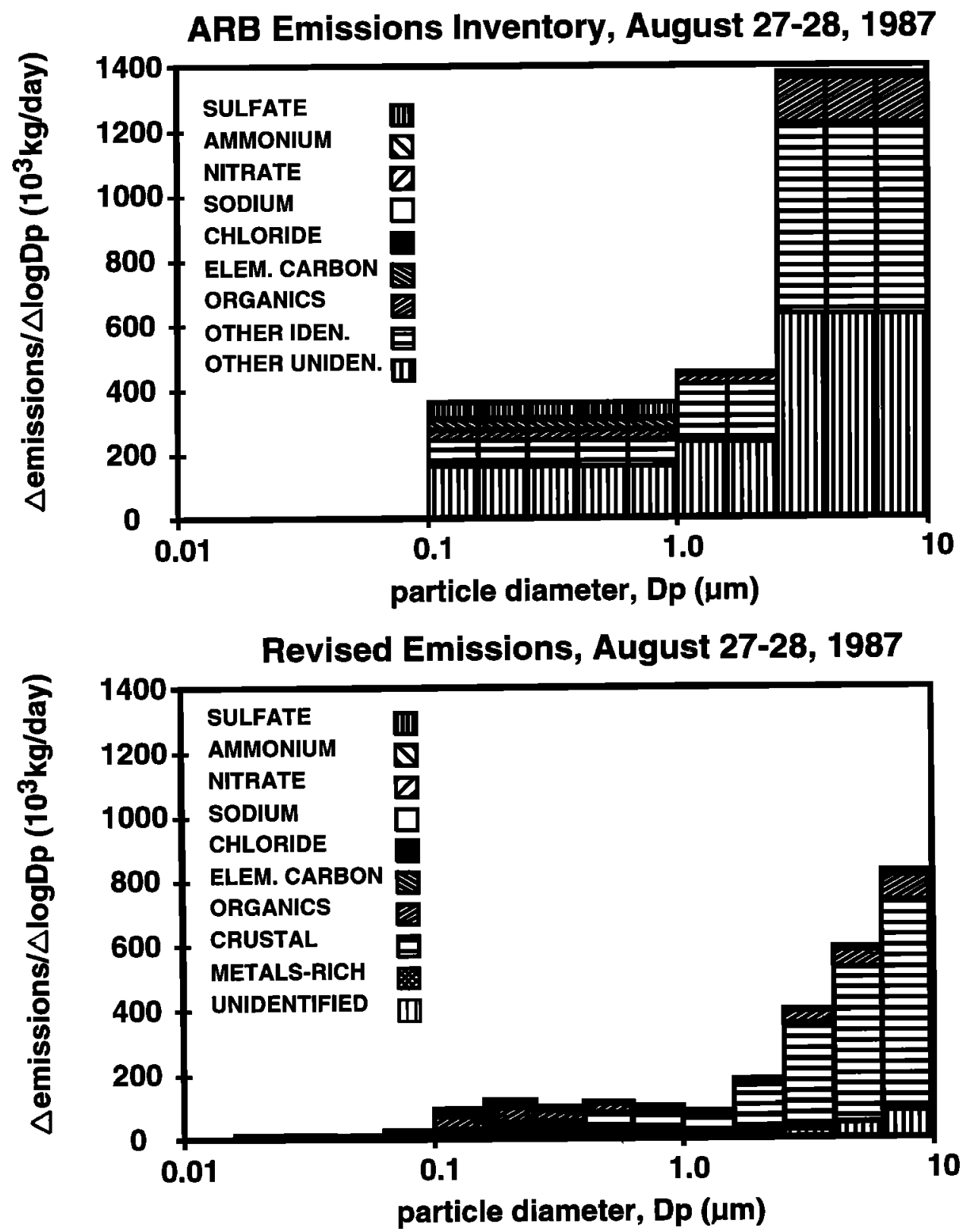

Figure 3. The size distribution and chemical composition of particulate matter emissions within the southern California area mapped in Figure 2: (a) official State of California Air Resources Board (ARB) emission inventory, compared to (b) emissions estimated in the present study. The ARB emission inventory does not specify a lower limit on the particle size distribution in the submicron range; here we graph the ARB emissions as if the submicron particles are principally in the size range from $0.1-$ to $1.0-\mu \mathrm{m}$ particle diameter.

tional Airport both at 0250 and 0355 PST that night. A second, widely reported fog event occurred throughout the central Los Angeles basin. This fog was first reported at Los Angeles International Airport at 0000 and eventually grew until it was reported at seven airports simultaneously by 0600 on August 28 , as shown in Figure 2. That fog later dissipated with its last report at Hawthorne at 1000 PST that day. Trajectories arriving at Claremont between 1200 and 1700 PST on August 28 clearly spent several hours over land within that fog. An example of one trajectory's location relative to that fog at 0600 on August 28 is shown in Figure
2. Finally, trajectories arriving at Claremont between 1800 and 2400 PST on August 28 stagnated overnight over the ocean but near the coast within Santa Monica Bay at a time when fog was reported at coastal airports. $\mathrm{SO}_{2}$ emissions occur in that region and within our model due to ships in the offshore shipping lanes. Whether or not these parcels that stagnated over Santa Monica Bay were engulfed in fog overnight is not known for sure, but it seems probable.

An objective procedure was adopted for determining when an air parcel enters or exits one of these fogs within our air quality model. The FAA fog reports from 


\section{INITIAL CONDITIONS}

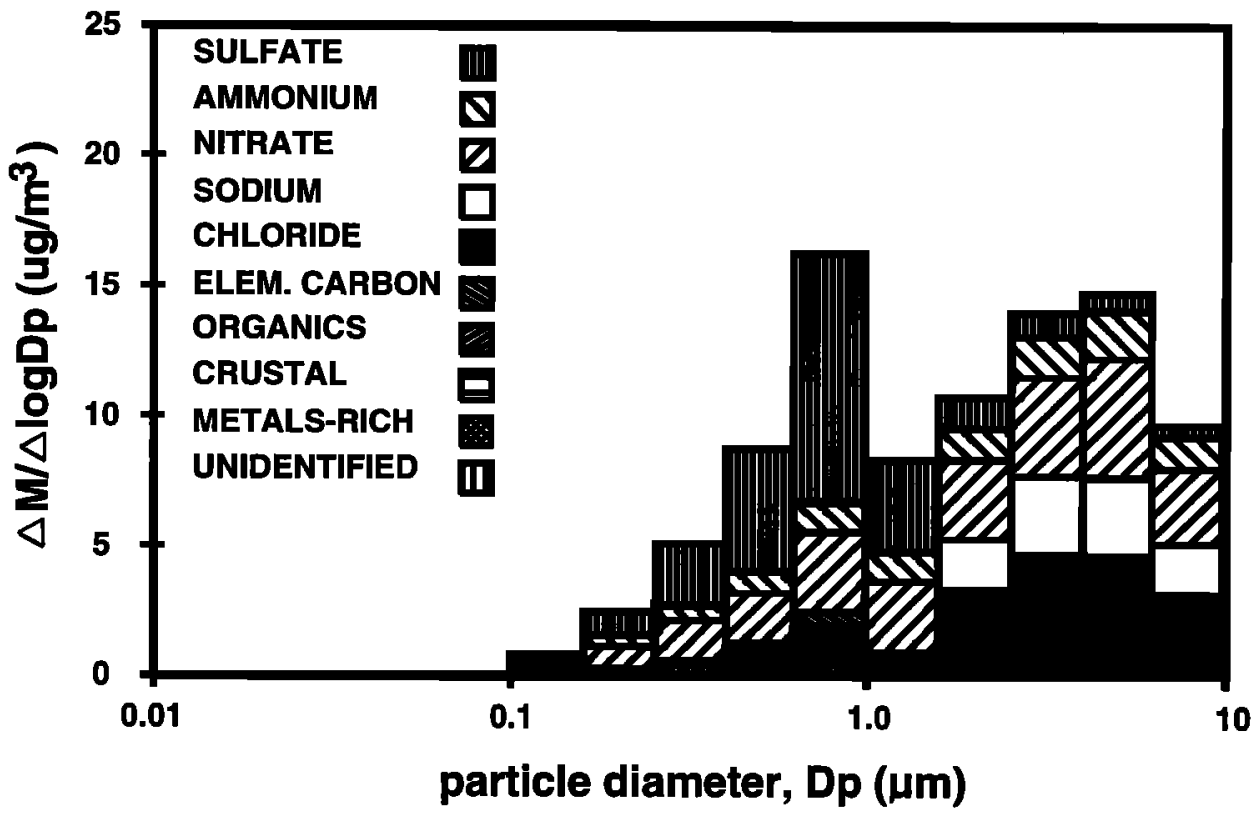

Figure 4. Aerosol mass distribution, $\triangle M / \triangle \log D_{p}$, describing initial conditions for particulate matter as a function of particle diameter, $\mathrm{D}_{p}$, and chemical composition.

all airports located upwind of Claremont were gathered for August 27 and 28. A separate map was prepared for each hour of those two days on which each airport was coded as reporting fog, reporting no fog, or not reporting data at all (i.e., closed to operations). A mark was made on each map at half the distance between those airports reporting fog and adjacent airports reporting no fog. Contour lines then were drawn to enclose the airports reporting fog by connecting the marks made at half the distance to sites reporting no fog. An air parcel then was determined to encounter the fog when it crossed into the boundary of one of these fog zones, and the fog was assumed to dissipate within that air parcel when the parcel later exited the fog zone boundary.

One inconsistency in the SCAQS database merits attention at this point. The relative humidity $(\mathrm{RH})$ values obtained by interpolation to the location of the air parcel trajectories typically are well below $100 \% \mathrm{RH}$ at the time that fogs were reported. Since relative humidity can never go above $100 \%$, any RH field created from time averaged data that are next interpolated spatially between sparse measurements (some of which are below $100 \% \mathrm{RH}$ ) will show $\mathrm{RH}$ values less than $100 \%$ nearly everywhere. Nevertheless, the FAA observers distinguish between haze and smoke (i.e., smog) and a true fog, and fogs were so widely reported by independent observers that the fog occurrence cannot be dismissed. To explore the possible effect of variations in the extent of the fogs, two test cases will be examined using the visibility model: (1) fog is considered to occur at all times when an air parcel is within a reported fog (base case assumption) and (2) fog is only considered to occur when fog is reported and the relative humidity interpolated to the interior of the air parcel is above $70 \%$.

\section{Fog Calculations}

The fog chemical model employed here requires that $p \mathrm{H}$ values and $\mathrm{Fe}(\mathrm{III})$ and $\mathrm{Mn}$ (II) metal concentrations be known. The atmospheric total iron and manganese concentrations were measured during the SCAQS experiment, but the valence state of these metals is not known. However, fog water samples in the Los Angeles area have been examined on other occasions by Erel et al. [1993]. Their data show that on average, $49 \%$ of the atmospheric iron in fog water typically is present as $\mathrm{Fe}$ (III) in unfiltered fogs and cloud water samples collected in the Los Angeles basin. Therefore the $\mathrm{Fe}$ (III) and $\mathrm{Mn}$ (II) concentrations in the fog were set by first consulting the filter-based measurements of total Fe and total Mn in fine particles in the SCAQS network filter samples closest in time and space to the place where each trajectory enters a fog zone, and then assuming that $49 \%$ of the $\mathrm{Fe}$ was present as $\mathrm{Fe}$ (III) and that $49 \%$ of the $\mathrm{Mn}$ was present as $\mathrm{Mn}$ (II). Likewise, fog $p \mathrm{H}$ cannot be calculated reliably from the SCAQS database as we do not know precisely how much alkaline material may have been present in the particle phase that would affect $p \mathrm{H}$ upon its dissolution. The $p \mathrm{H}$ of fogs in the Los Angeles area also has been examined extensively by Erel et al. [1993], Jacob et al. [1985], Munger et al. [1983], and Waldman [1985]. Their data show that fog $p \mathrm{H}$ falls in the range of 2.22 to 5.25 . A central value of $p \mathrm{H} 4.0$ is adopted for use in our base case calculations, and the sensitivity of model calculations to variations in $p \mathrm{H}$ will be explored. Aerosol particles are activated in accordance with an assumed water vapor supersaturation of $0.08 \%$ and grow to an assumed $20-\mu \mathrm{m}$ diameter while in the fog. When the fog dissipates, the water content of each droplet is reduced 
to that of an aerosol particle containing small amounts of water, then the AIM inorganic species transport code is used to redistribute volatile pollutant species and water vapor between the gas and the particle phases at the relative humidity observed after the fog has dissipated.

\section{Model Results}

The emissions and meteorological data were assembled for use in the trajectory-based visibility model. Aerosol concentration, size distribution, chemical composition, and light scattering by particles then were computed for each of 24 trajectories of 48-hour duration arriving hourly at Claremont on August 28, 1987. The base case calculations presented first represent results obtained for the case with fog calculations invoked at all hours when fog was reported by human observers at area airports. Results are presented for important gas phase species, aerosol mass concentrations and the concentration of individual aerosol components, as well as the size distribution of important aerosol chemical species, overall aerosol size distributions, particle lightscattering calculations, and visual range predictions.

\section{Gas Phase Species}

Figure 5 shows time series plots of predicted and measured ozone, as a measure of the level of the gas phase photochemistry, and $\mathrm{NO}_{2}$, an important ozone precur- sor and light absorbing gas. Time series plots of ammonia and nitric acid are also presented, as they play an important role in secondary inorganic aerosol formation. The ozone predictions fall below the observed values at Claremont, a result that is substantially identical to previous model results obtained for ozone at Claremont during the SCAQS August 27-28 episode [Harley et al., 1993a] even when modeled ozone concentrations at other sites in the air basin generally are in quite close agreement with observed values. The role of ozone and other photochemical oxidants in the present visibility model is to assist the heterogeneous oxidation of $\mathrm{SO}_{2}$ to form sulfates in fog droplets. It will be seen shortly that in spite of the underprediction of ozone levels, oxidant concentrations are still high enough to convert virtually all of the available $\mathrm{SO}_{2}$ to form sulfates when a fog occurs in the higher $p H$ sensitivity tests. Therefore the underprediction of the ozone concentrations does not greatly affect the present visibility model. The model predictions for $\mathrm{NO}_{2}$ fall in the middle of the range of values reported by two colocated $\mathrm{NO}_{2}$ monitors at Claremont with some overprediction during nighttime periods. Gaseous nitric acid predictions have a bias of less than $1 \mathrm{ppb}$ when compared with measurements made over consecutive 4- to 7-hour sampling periods using the denuder difference system for $\mathrm{HNO}_{3}$ built into the SCAQS sampler [Fitz et al., 1989; $\mathrm{Her}$ ing et al., 1988; Solomon et al., 1988]. Both observed
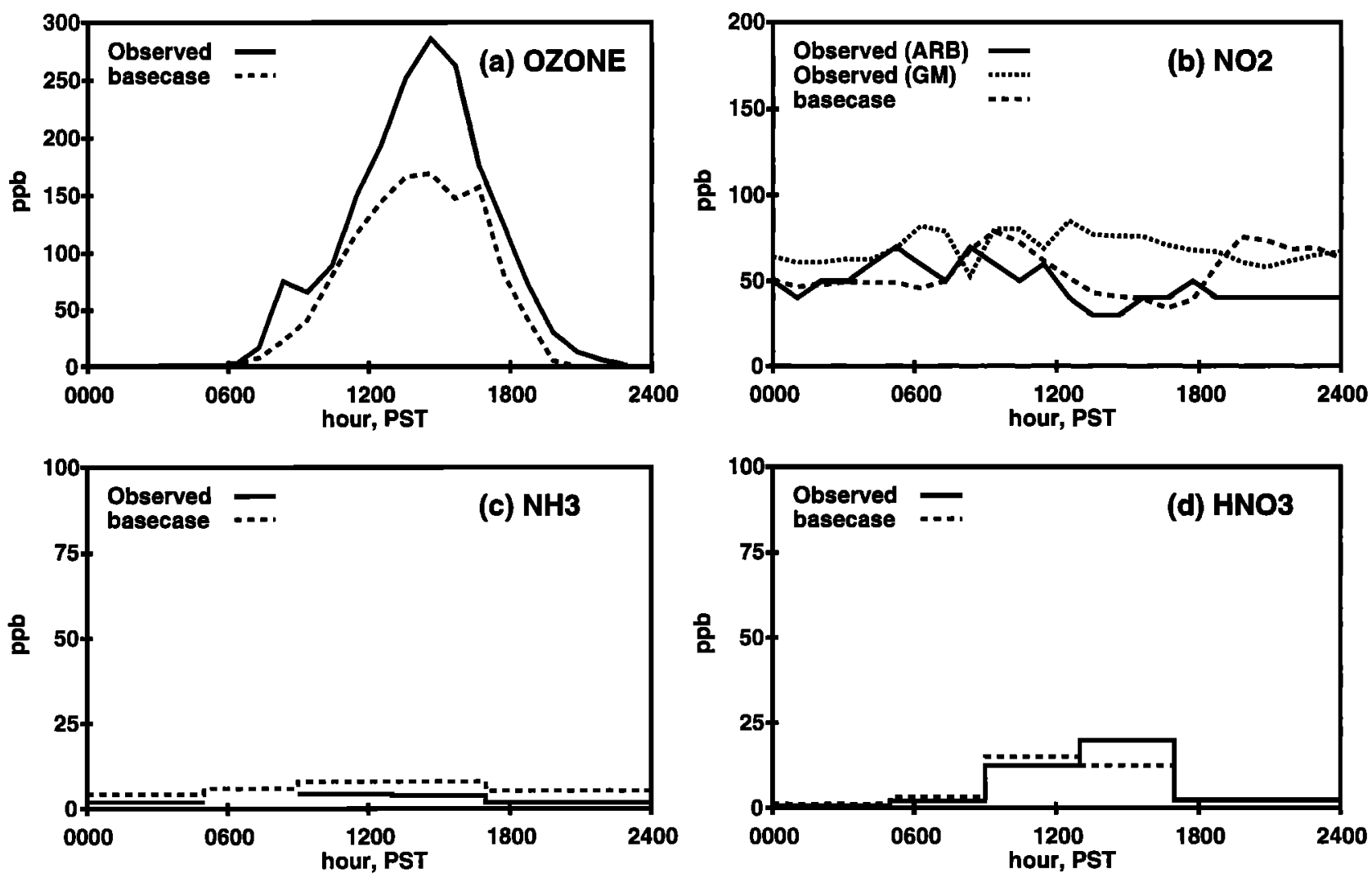

Figure 5. Time series plots of observed and predicted gas phase pollutant concentrations on August 28, 1987, at Claremont, California: (a) $\mathrm{O}_{3}$, (b) $\mathrm{NO}_{2}$, (c) $\mathrm{NH}_{3}$, and (d) $\mathrm{HNO}_{3}$. The $\mathrm{NO}_{2}$ predictions shown here include $\mathrm{NO}_{2}$ plus all other reactive nitrogen compounds that are measured as if they were $\mathrm{NO}_{2}$ by chemiluminescent monitors. 
and predicted gaseous ammonia concentrations are of the order of a few parts per billion.

\section{Aerosol Mass Concentration}

Time series plots of the observed and predicted PM2.5 and PM10 aerosol mass concentration for the base case are shown in Figure $6 \mathrm{a}$ and $6 \mathrm{~b}$. These measurements of aerosol mass concentration were made by filtration using the SCAQS sampler over 4- to 7-hour periods. Model results are averaged over the same 4- to 7-hour time periods while grouping all particles in the model having diameters less than $2.5 \mu \mathrm{m}$ and less than $10 \mu \mathrm{m}$. The mean of the five measured PM2.5 concentrations shown in Figure $6 \mathrm{a}$ is $61 \mu \mathrm{g} \mathrm{m}^{-3}$, while the corresponding predicted PM2.5 concentration from the model is 62 $\mu \mathrm{g} \mathrm{m}^{-3}$. The mean of the five measured PM10 concentrations is $97 \mu \mathrm{g} \mathrm{m}^{-3}$, while the corresponding predicted PM10 concentration from the model is $102 \mu \mathrm{g} \mathrm{m}^{-3}$. The mass present in the PM10 and PM2.5 size fractions oscillates about the observed values with modeled values greater than or equal to observations in three time periods and model predictions lower than observations in two time periods. A statistical summary of the comparison between model predictions and observations for the base case simulation is given in the first rows of Table 4.

\section{Individual Aerosol Species}

Figures $6 \mathrm{c}$ through $6 \mathrm{~h}$ show time series plots of observations and model predictions of the PM2.5 or PM10
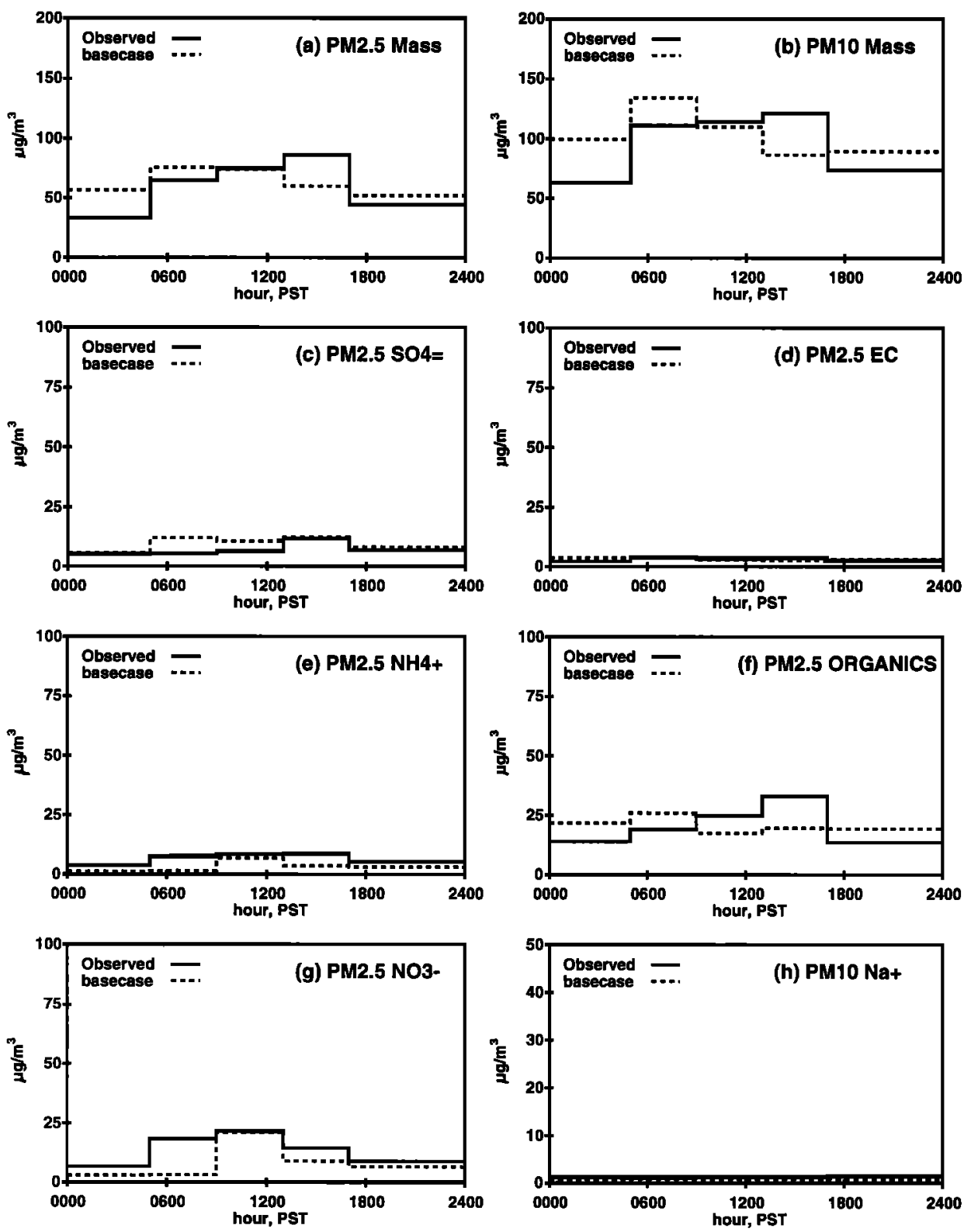

Figure 6. Time series plots of observed and predicted particle phase concentrations on August 28, 1987, at Claremont, California: (a) PM2.5 mass, (b) PM10 mass, (c) PM2.5 $\mathrm{SO}_{4}^{\overline{4}}$, (d) PM2.5 elemental carbon (EC), (e) PM2.5 NH+ , (f) PM2.5 organics, (g) PM2.5 NO$-\mathrm{NO}_{3}^{-}$, (h) PM10 Na${ }^{+}$. 
Table 4. Analysis of Model Performance

\begin{tabular}{|c|c|c|c|c|c|c|c|c|}
\hline Case & $\begin{array}{c}\text { PM2.5 Mass } \\
{\left[\text { Mean] }{ }^{a}\right.} \\
\text { Bias }^{b} \\
\text { (s.d.) }\end{array}$ & PM10 Mass & $\underset{(\mathrm{PM} 2.5)}{\mathrm{EC}}$ & $\begin{array}{r}\text { Organics } \\
(\mathrm{PM} 2.5)\end{array}$ & $\begin{array}{c}\mathrm{SO}_{4}^{=} \\
(\mathrm{PM} 2.5)\end{array}$ & $\begin{array}{c}\mathrm{NH}_{4}^{+} \\
(\mathrm{PM} 2.5)\end{array}$ & $\begin{array}{c}\mathrm{NO}_{3}^{-} \\
(\mathrm{PM} 2.5)\end{array}$ & $\begin{array}{c}\mathrm{Na}^{+} \\
(\mathrm{PM} 10)\end{array}$ \\
\hline $\begin{array}{l}\text { Observed } \\
\text { mean }\end{array}$ & [60.90] & [ 97.04] & [ 3.19] & [ 20.99] & {$[7.16]$} & [ 6.79] & [ 14.22] & [ 1.46] \\
\hline $\begin{array}{l}\text { Base case } \\
\text { Model }\end{array}$ & 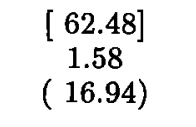 & $\begin{array}{c}{[101.90]} \\
4.86 \\
(24.19)\end{array}$ & 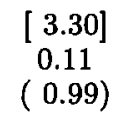 & 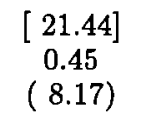 & $\begin{array}{c}{[10.34]} \\
3.18 \\
(2.87)\end{array}$ & $\begin{array}{c}{[2.77]} \\
-4.02 \\
(1.77)\end{array}$ & $\begin{array}{c}{[6.64]} \\
-7.58 \\
(4.76)\end{array}$ & $\begin{array}{c}{[0.86]} \\
-0.60 \\
(0.27)\end{array}$ \\
\hline Lower $p H$ & 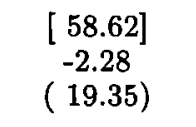 & $\begin{array}{c}{\left[\begin{array}{l}98.04 \\
1.00 \\
(26.42)\end{array}\right.}\end{array}$ & $\begin{array}{c}{[3.30]} \\
0.11 \\
(0.99)\end{array}$ & $\begin{array}{c}{[21.44]} \\
0.45 \\
(8.17)\end{array}$ & $\begin{array}{c}{[6.36]} \\
-0.80 \\
(1.47)\end{array}$ & $\begin{array}{c}{[2.79]} \\
-4.00 \\
(1.79)\end{array}$ & $\begin{array}{c}{[6.62]} \\
-7.60 \\
(4.82)\end{array}$ & $\begin{array}{c}{[0.85]} \\
-0.60 \\
(0.28)\end{array}$ \\
\hline Higher $p \mathrm{H}$ & 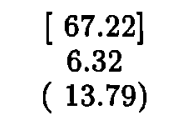 & $\begin{array}{c}{[106.64]} \\
9.60 \\
(21.28)\end{array}$ & 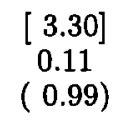 & 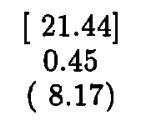 & 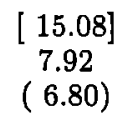 & $\begin{array}{c}{[2.74]} \\
-4.05 \\
(1.77)\end{array}$ & $\begin{array}{c}{[6.66]} \\
-7.56 \\
(4.76)\end{array}$ & $\begin{array}{c}{[0.86]} \\
-0.60 \\
(0.27)\end{array}$ \\
\hline Less fog & $\begin{array}{c}{[60.50]} \\
-0.40 \\
(16.57)\end{array}$ & $\begin{array}{c}{[100.68]} \\
3.64 \\
(23.95)\end{array}$ & $\begin{array}{c}{\left[\begin{array}{c}3.31 \\
0.12 \\
(0.99)\end{array}\right.}\end{array}$ & 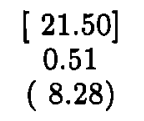 & $\begin{array}{c}{[7.86]} \\
0.70 \\
(2.45)\end{array}$ & $\begin{array}{c}{[2.73]} \\
-4.05 \\
(1.76)\end{array}$ & $\begin{array}{c}{[6.78]} \\
-7.44 \\
(5.06)\end{array}$ & $\begin{array}{c}{[0.86]} \\
-0.59 \\
(0.28)\end{array}$ \\
\hline $\begin{array}{l}\text { Increased } \\
\text { Initial } \\
\text { Conditions }\end{array}$ & 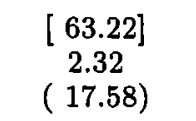 & $\begin{array}{c}{[102.88]} \\
5.84 \\
(25.34)\end{array}$ & 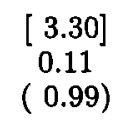 & 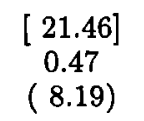 & $\begin{array}{c}{[10.18]} \\
3.02 \\
(2.77)\end{array}$ & $\begin{array}{c}{[3.20]} \\
-3.58 \\
(1.82)\end{array}$ & 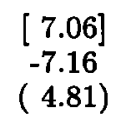 & 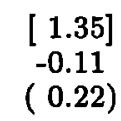 \\
\hline $\begin{array}{l}\text { Increased } \\
\text { Reactive } \\
\text { Organics }\end{array}$ & 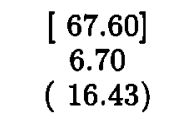 & $\begin{array}{c}{[107.04]} \\
10.00 \\
(23.40)\end{array}$ & 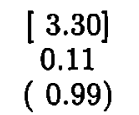 & 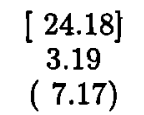 & $\begin{array}{c}{[10.40]} \\
3.24 \\
(2.87)\end{array}$ & $\begin{array}{c}{[3.56]} \\
-3.23 \\
(2.01)\end{array}$ & 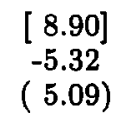 & $\begin{array}{c}{[0.85]} \\
-0.60 \\
(0.28)\end{array}$ \\
\hline
\end{tabular}

\footnotetext{
${ }^{a}$ Unweighted mean of five pairs of predictions and observations corresponding to the five sampling intervals shown in
} Figures 6 and 7; all values in micrograms per cubic meter.

${ }^{b}$ Predicted - observed, micrograms per cubic meter.

${ }^{c}$ Standard error of residuals, micrograms per cubic meter.

aerosol mass concentration of important individual chemical species. Again, the measured values are from the SCAQS filter-based sampler located at Claremont. The fine particle $\mathrm{NO}_{3}^{-}$data are taken by the denuder difference method in order to avoid sampling artifacts, and the $\mathrm{NH}_{4}^{+}$data have been corrected to the same basis as the nitrate data [see Eldering et al., 1994]. The time series for elemental carbon is shown in Figure 6d. Elemental carbon is not produced by any secondary atmospheric chemical reactions and it is not removed from the atmosphere easily by dry deposition due to the size of the particles. There is excellent agreement between the observations and the predictions for elemental carbon, with a bias of $0.1 \mu \mathrm{g} \mathrm{m}^{-3}$ suggesting that transport calculations for fine particles are acceptable and that the emission inventory is reasonably accurate. Organic material is a combination of primary material and secondary organic aerosols. The model predictions of PM2.5 organic material concentrations (Figure 6f) are in close agreement with observations with mean predicted concentrations for the base case of $21 \mu \mathrm{g} \mathrm{m} \mathrm{m}^{-3}$ versus a measured concentration of $21 \mu \mathrm{g} \mathrm{m}^{-3}$, as shown in Table 4. Overprediction occurs in three sampling periods and underprediction in two sampling periods.
Aerosol sulfate is emitted as a primary aerosol constituent and is produced through the oxidation of $\mathrm{SO}_{2}$ in the atmosphere. Base case model predictions are within $10 \%$ of observations for aerosol sulfate during three sampling periods, with small overprediction of sulfate concentrations during two sampling periods.

Sensitivity analyses using the model show that predicted sulfate ion mass concentrations are most strongly affected by the number of hours that a trajectory is within a fog and the $p \mathrm{H}$ of the fog droplet. Predicted PM2.5 sulfate concentrations will be discussed for three sensitivity tests. Sensitivity tests were run at higher and

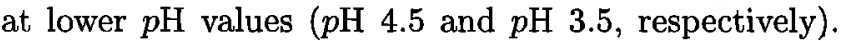
Also presented are results at $p \mathrm{H} 4$ with fog invoked only when both fog was reported by FAA observers and the $\mathrm{RH}$ interpolated to the interior of the trajectory cell was greater than $70 \%$ ("less fog"). Model predictions of average sulfate concentrations vary by \pm 4 to 4.7 $\mu \mathrm{g} \mathrm{m}^{-3}$ as the $p \mathrm{H}$ is varied, decreasing with decreasing $p \mathrm{H}$. The simulation using less extensive fogs ("less fog") results in a noticeable decrease in predicted PM2.5 sulfate concentrations during the second sampling period of the day (0500-0900), a slight decrease in predictions during the third sampling period (0900-1300), and no 
change in the predictions for the other sampling periods and yields excellent agreement between predicted and observed sulfate concentrations. A statistical summary of model performance for the case of each sensitivity test is given in Table 4.

Model predictions of PM2.5 $\mathrm{NO}_{3}^{-}$concentrations are controlled by the total amount of inorganic nitrate ever produced within the air parcel, by the gas phase concentrations of ammonia, and by the amount of $\mathrm{Na}^{+}$ from sea salt available to form coarse particle nitrates. Figure $6 \mathrm{~h}$ and Table 4 show that the PM10 Na+ concentration is reproduced to within about $0.6 \mu \mathrm{g} \mathrm{m}^{-3}$. Figure 5 shows that gas phase $\mathrm{NH}_{3}$ concentrations predicted by the model are higher than observed values. Model predictions for aerosol nitrate shown in Figure $6 \mathrm{e}$ fall substantially below observed values during the second sampling period (about $15 \mu \mathrm{g} \mathrm{m}^{-3}$ ) and somewhat below observations at other times (about $3 \mu \mathrm{g} \mathrm{m}^{-3}$ on average). This underprediction of aerosol nitrate is due in part to the slight underprediction of $\mathrm{Na}^{+}$levels and in part to a shortage of total inorganic nitrate (i.e., $\mathrm{HNO}_{3}$ ever produced by the model).

To quantitatively examine the effect of increased seasalt concentrations and increased nitric acid production within the model on aerosol nitrate formation and on model results in general, two sensitivity analyses were conducted. First, sodium and chloride concentrations within the initial conditions supplied to the model were increased by $30 \%$, which is sufficient to remove most of the bias in $\mathrm{Na}^{+}$predictions at Claremont, as seen in Table 4. Average coarse aerosol nitrate increases by $1.1 \mu \mathrm{g} \mathrm{m}^{-3}(11 \%)$ in that case, and fine aerosol nitrate increases by a smaller amount, about $0.4 \mu \mathrm{g} \mathrm{m}^{-3}$. In a separate sensitivity test, the emissions of reactive organic gases into the trajectory model were increased by $50 \%$, which is sufficient to reduce the bias in ozone predictions to $1 \mathrm{ppb}$. In this case, PM2.5 nitrate concentrations increase by $34 \%$ relative to the base case results, and ammonium ion concentration predictions increase as well, but both still are lower than the observed PM2.5 ammonium and nitrate concentrations. In the case with increased organic vapor emissions, the PM2.5 organics concentrations increase to $3 \mu \mathrm{g} \mathrm{m}^{-3}$ above observed concentrations due to increased secondary organic aerosol formation.

\section{Comparison With Impactor Measurements}

Figure 7 shows a comparison of size-distributed aerosol species concentrations and model predictions. Impactor measurements of the size-distributed aerosol concentrations of sodium, nitrate, ammonium, and sulfate ion were made by John et al. [1989] with nine-stage Berner impactors at Claremont during SCAQS. Zhang et al. [1993] used microorifice uniform deposit impactors (MOUDIs) to measure organic and elemental carbon particle size distributions at Claremont during SCAQS. Both sets of impactor measurements were made over the same sampling periods as the SCAQS filter samples with the exception of the first sampling period of the day, during which no impactor measurements were made. The model predictions which arise from particles in 15 different diameter intervals are cast into the same format as the impactor data by first graphing the model results as a step function volume diagram of $\Delta V / \Delta \log$ $\mathrm{D}_{p}$, then slicing that diagram at the cut points between the various impactor stages, followed by summing like species in each impactor size interval.

The impactor measurements and model predictions for elemental carbon agree well. Most of the elemental carbon is present in particles less than $1 \mu \mathrm{m}$ in diameter, consistent with the domination of emissions of elemental carbon by sources such as diesel engines. The observations and model predictions for the relative size distribution of organic material are also in agreement, with most of the material present in particles between 0.1 and $1.0 \mu \mathrm{m}$ in diameter, while the absolute magnitude of the organic aerosol concentration measured by the impactor falls below that predicted by the model (note from Figure 6f that the model is in closer agreement with the filter-based organic aerosol concentration measurements at this time).

The impactor measurements of sodium ion show a progressive increase with increasing particle diameter with the majority of material in particles larger than 1 $\mu \mathrm{m}$ in diameter. The model predictions place most of the material in particles larger than $1 \mu \mathrm{m}$ for both sampling periods. The impactor measurements and model predictions for $\mathrm{NH}_{4}^{+}$and $\mathrm{SO}_{4}^{=}$show size distributions that peak just below $1 \mu \mathrm{m}$ in diameter, reflecting the droplet mode formed by the fog water chemical reactions.

Impactor measurements of $\mathrm{NO}_{3}^{-}$during the midday sampling period (0900-1300 PST) show a fine particle peak just below $1 \mu \mathrm{m}$ and a smaller coarse particle peak located between about 2 and $10 \mu \mathrm{m}$ in diameter. The model predictions also show two peaks, although their height and location do not exactly match the impactor measurements. The nighttime nitrate size distribution shown in Figure 7 as measured by the impactor is flatter, as is the shape of the size distribution predicted by the model. The shortfall in predicted coarse particle nitrates mirrors the relative underprediction of $\mathrm{Na}^{+}$at that time. $\mathrm{Na}^{+}$concentrations are almost impossible to predict with greater accuracy because upwind seasalt initial conditions are not known with tremendous accuracy.

To describe the differences and similarities between the impactor measurements and the model predictions, the frequency distribution of residual values was calculated over all impactor stages and all hours of simulation for the base case model calculations, altered $p \mathrm{H}$, and altered fog duration sensitivity tests. A single residual is defined as the model prediction minus the observed value for a single impactor stage. Figure 8 shows these frequency distribution plots for elemental carbon, organic material, $\mathrm{Na}^{+}, \mathrm{NH}_{4}^{+}$, and $\mathrm{NO}_{3}^{-}$. Residual plots for $\mathrm{SO}_{4}^{-}$are shown for the base case model with a fog $p \mathrm{H}$ of 4 , for fog $p \mathrm{H}$ at 3.5 and 4.5 , and for the sensitivity test with a less extensive fog. The narrow frequency distributions for elemental carbon and sodium reflect the good agreement between impactor measure- 

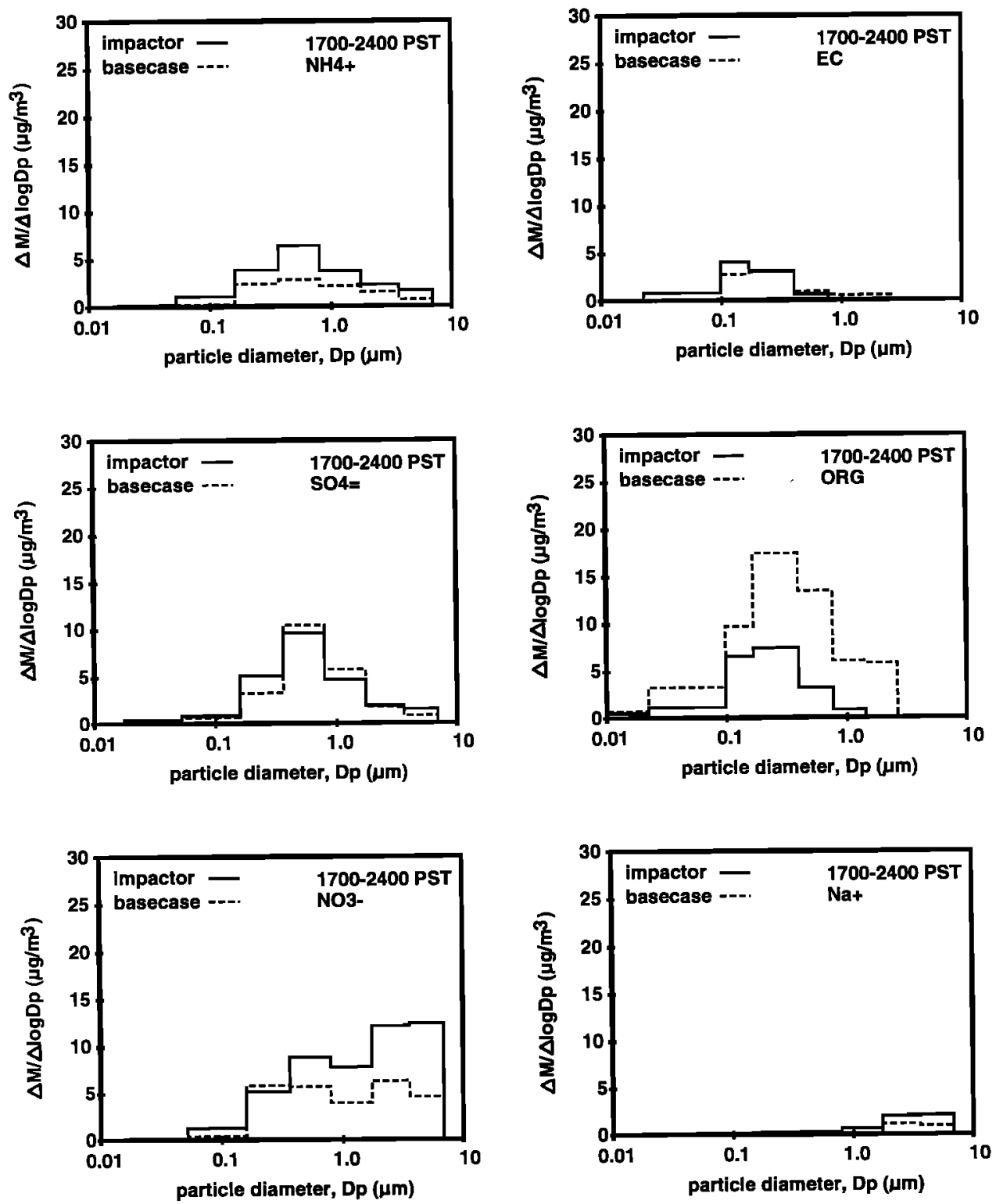

Figure 7. Base case model predictions of the mass distribution, $\triangle M / \triangle \log D_{p}$, of individual chemical species compared to impactor measurements during the sampling period 1700-2400 PST on August 28, 1987, at Claremont, California.

ments and model predictions. The frequency distribution for organic material shows a number of positive residuals, reflecting overprediction by the model relative to some of the impactor measurements. It is important to recall that average predicted PM2.5 organic material concentrations match those measured by filter sampling very well; there are differences in organics concentrations measured by filtration versus impaction during SCAQS. The residual values are centered at 0.0 for $\mathrm{NH}_{4}^{+}$and $\mathrm{SO}_{4}^{=}$, indicating that the most frequent difference between model predictions and observations lies in the range $\pm 0.5 \mu \mathrm{g} \mathrm{m}^{-3}$ on each impactor stage. The underprediction of PM2.5 ammonium ion concentrations is reflected in the higher frequency of negative residuals than positive residuals. The frequency distribution of the residuals for $\mathrm{SO}_{4}^{-}$remains centered on zero in all three fog sensitivity cases studied. The frequency distribution of residual differences between PM2.5 nitrate impactor measurements and model predictions is distributed over a larger range, reflecting the fact that observed $\mathrm{NO}_{3}^{-}$concentrations are underpredicted by the model and associated emission data, while most other species are matched very closely.

\section{Aerosol Size Distribution}

In the present application a trajectory-based model was configured to predict the mass concentrations of the most important aerosol species at 15 discrete particle sizes over the size range from $0.01-$ to $10-\mu \mathrm{m}$ particle diameter. An overall aerosol volume distribution can be drawn from this information, by graphing the incremental particle volume $\Delta V$ represented by particles in each size class divided by the width of the logarithmic particle size interval $\Delta \log D_{p}$, defined by the $\log$-mean 


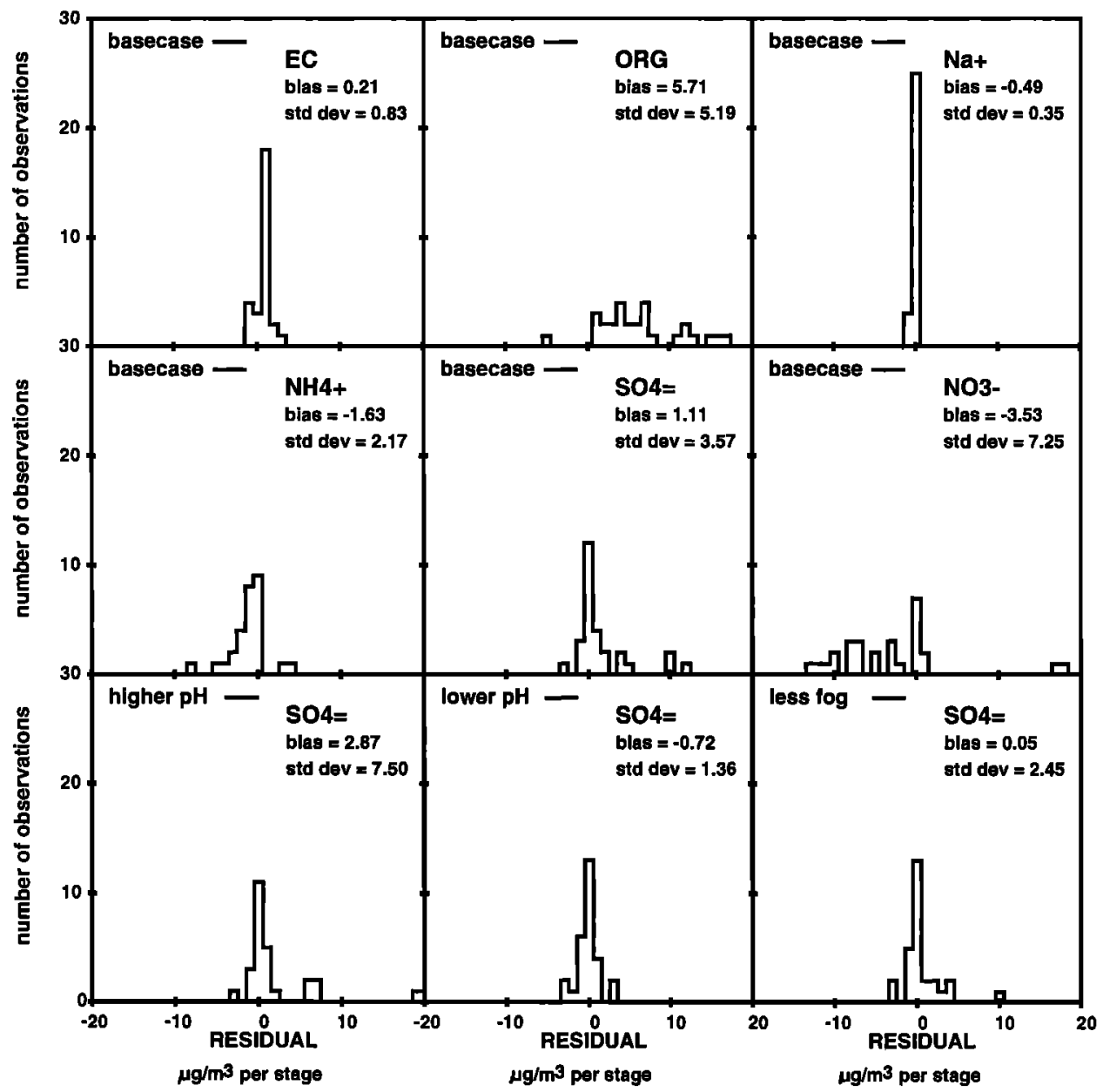

Figure 8. Histograms of the frequency of occurrence of concentration residuals (predicted minus observed) determined for all individual impactor stages and all times during August 28, 1987, at Claremont, California. The bias (mean residual difference) between predictions and observations for all impactor stages is given for each chemical species in micrograms per cubic meter along with the standard deviation of the population of those residuals.

diameter difference between particles of that size and its nearest neighboring particle size classes. Figure $9 \mathrm{a}$ shows the aerosol volume distribution $\left(\triangle \mathrm{V} / \triangle \log \mathrm{D}_{p}\right)$ as measured by electrical aerosol analyzers (EAA) and optical particle counters (OPC) at Claremont. The observed aerosol volume distribution presented over the size range from $0.01-\mu \mathrm{m}$ to $2.83-\mu \mathrm{m}$ particle diameter is from the combined data taken with a TSI model 3030 EAA and a PMS LAS-X OPC as described by Eldering et al. [1994]. The measured aerosol size distribution shown here has been extended so that the coarse fraction volume in particles from $2.5-$ to $10-\mu \mathrm{m}$ diameter matches the volume inferred from simultaneous filterbased measurements of aerosol properties (see Eldering et al., [1994], case B; there is only one overall measured value of $\Delta V / \Delta \log D_{p}$ in the coarse particle size range and that value is a 7 -hour average that is not specific to the arrival time of a single air parcel).

The aerosol size distribution and chemical composition predicted by the model is presented in Figure 9b for the base case for the trajectory arriving at Claremont at 1700 PST. Model predictions for other hours are presented by Eldering [1994]. The model predictions in Figure $9 \mathrm{~b}$ have been graphed after removing aerosol water from the particles since it has been determined previously that the size distribution instruments at Claremont dried out the aerosol while making their measurements [Eldering et al., 1994]. The size distribution measurements have greater size resolution than the model in the fine particle mode, while the model has greater size resolution than the measurements in the coarse particle mode, so exact agreement cannot be achieved, but the comparison nevertheless is instructive. The measured aerosol size distributions have two distinct submicron modes, one at just above $0.1-\mu \mathrm{m}$ particle diameter and another at just below $1.0-\mu \mathrm{m}$ particle diameter. The model predictions, although they contain less size resolution in the submicron range, show a similar shape. The aerosol size distributions created by the base case model predict that there is little aerosol volume below $0.1 \mu \mathrm{m}$, a peak just below $1.0 \mu \mathrm{m}$, and a substantial volume of material between 2.5- and 10$\mu \mathrm{m}$ particle diameter. This figure illustrates how the ionic material, organics, elemental carbon, crustal ma- 

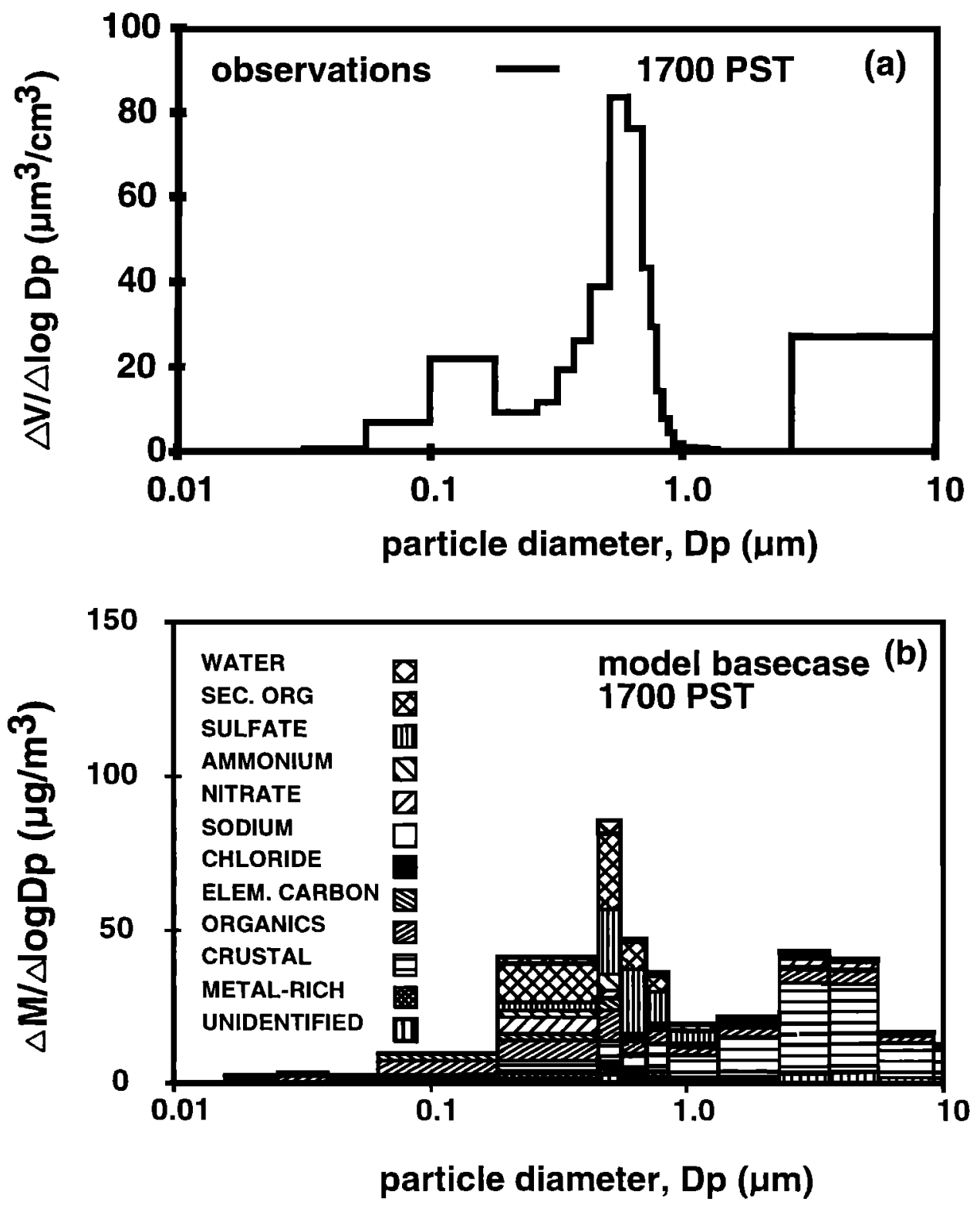

Figure 9. Comparison of measured and predicted aerosol size distributions: (a) aerosol size distribution as measured by electrical aerosol analyzers, optical particle counters, and filter samplers at Claremont at 1700 PST on August 28, 1987; (b) the size distribution of aerosol chemical composition as predicted by the base case model at Claremont, California, on August 28, 1987, at 1700 PST.

terial, and water fit together to shape the overall aerosol size distribution. Particles with diameters between 0.1 and $1.0 \mu \mathrm{m}$ contain significant amounts of elemental carbon, organic material, $\mathrm{SO}_{4}^{-}, \mathrm{NH}_{4}^{+}, \mathrm{NO}_{3}^{-}$, secondary organic aerosol, metal-rich industrial primary particles, and unidentified material. The larger particles (greater than $1 \mu \mathrm{m}$ in diameter) are dominated by crustal material, with some coarse particle $\mathrm{NO}_{3}^{-}$and organic material.

\section{Light-Scattering Coefficient}

Particle light-scattering coefficient values were measured during the SCAQS study using nephelometers by scientists from General Motors (GM) Research Labo- ratory and the University of Illinois (UI). These data sets are discussed in detail by Eldering et al. [1994]. A comparison of measured and modeled particle lightscattering coefficient values at Claremont for the base case model calculations is presented in Figure 10 at two different wavelengths. It is seen that predicted and observed light-scattering levels agree on average with a bias of $19 \%$ averaged over the two sets of observations and predictions and with the largest differences occurring at night near the end of August 28.

The total light extinction coefficient next was calculated by summing the light scattering by particles, light absorption by particles, light scattering by air molecules, and light absorption by the $\mathrm{NO}_{2}$ concentra- 

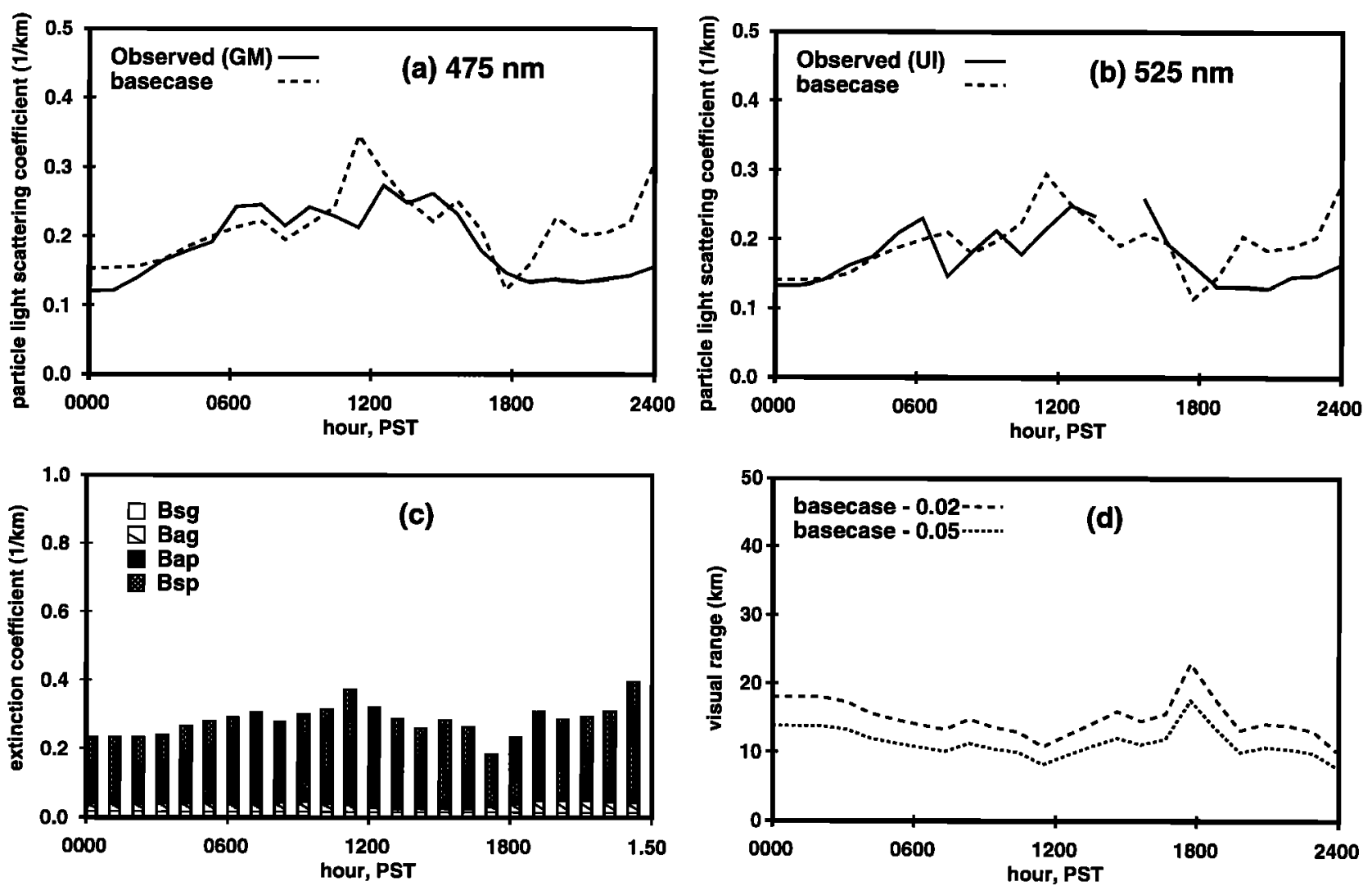

Figure 10. Observed and predicted light scattering by particles at (a) $475 \mathrm{~nm}$ and (b) $525 \mathrm{~nm}$. Contributions to the total extinction coefficient (c) are translated into visual range estimated using Koschmieder's formula (d) for two values of the threshold contrast for human observers (0.02 and 0.05).

tions predicted by the model. The contribution of each of these terms to the total light extinction coefficient is illustrated in Figure 10c. This time series of the light extinction coefficient values was translated into estimated visual range values using Koschmieder's formula [Middleton, 1952] with threshold contrast values of 0.02 and 0.05 . The threshold constant of 0.02 was originally employed by Koschmieder for visual range calculations, although a value of 0.05 produces better agreement with reported visual range observations [Gordon, 1984]. It is seen that the visual range at Claremont was estimated to be in the range of 8 to $21 \mathrm{~km}$ over the August 28 period studied.

\section{Discussion}

The source-oriented air quality model developed in the present paper possesses a number of advantages that make it an attractive tool for studying the effect of pollutant emissions on visibility-related phenomena. First, the model is based on fundamental descriptions of physical processes, including size- and chemically distributed emissions, atmospheric transport, chemical reaction, transport of condensible secondary reaction products to and from the aerosol, fog chemistry, dry deposition, and light scattering and absorption. Such a mechanistic formulation confers the advantage that fundamental laws, such as mass conservation, are ob- served and, in principle, allows the model to be used to examine meteorological conditions and distributions of emission sources beyond the range of the historical conditions to which purely empirical models, such as rollback models, are confined.

The Lagrangian discrete particle representation of the aerosol used here possesses several advantages that are important to the present application. The model can represent an arbitrary aerosol size distribution (i.e., it is not limited to lognormal size distributions). There is no need to calculate particle growth across artificial, fixed, aerosol size section boundaries. Some particles but not others can be activated by water condensation according to the aerosol size and chemical composition, and particles can grow to much larger sizes easily within a fog. Further, the discrete particle formulation possesses considerable flexibility that will lead easily to future modeling improvements: aerosol size resolution can be increased by defining initial particle sizes at more closely spaced intervals: the contributions of different sources can be distinguished from each other if desired by labeling primary seed particles according to their source; an externally mixed aerosol can be represented by tracking particles having different chemical composition separately.

The model also has advantages that are important to its use in studying visibility-related phenomena. The 
model provides instantaneous time resolution which is important because certain quantities such as visual range are not estimated accurately from time-averaged aerosol properties. Model outputs further are compatible with the input data requirements of visibility models that produce synthetic color photographs of the scene of interest [Eldering et al., 1993].

Finally, model construction has been closely coordinated with field experiments such that nearly all input parameters to the model can be obtained by experimental methods that are accessible in the literature. The size distributions and chemical compositions of emissions from the most important primary aerosol source types have been measured during a source testing campaign that is linked to this modeling effort [Hildemann et al., 1991a, b]. Ambient aerosol observations are from the SCAQS experiment, where methods were used that were specifically designed to support tests of aerosol and visibility model performance. Model performance testing for the aerosol quantities reported here is built upon years of testing of critical gas phase components of the model, including the $\mathrm{NH}_{3}$ emissions inventory [Russell and Cass, 1986], refinement of the organic vapor emission data [Harley et al., 1992] and testing of the ability of both meteorological and emission data to reproduce gas phase pollutant concentrations during the SCAQS episode examined here [Harley et al., 1993a, b; Harley and Cass, 1995].

These advantages of the model and its associated model evaluation data sets are accompanied by certain limitations. Inherent limitations of all Lagrangian trajectory models include the fact that they cannot represent horizontal turbulent diffusion, cannot represent effects of wind shear, and typically can represent vertical turbulent diffusion but not advection by vertical wind components. These limitations to transport calculations can, in test cases, generate errors of the order of $\pm 50 \%$ [Liu and Seinfeld, 1975], although the bias statistics of the present study suggest that average errors are not that large during the present model application. When a trajectory model is used as a visibility model, conditions are represented only over short distances where concentration gradients are small. This is adequate for evaluation of visibility phenomena under heavily polluted urban haze conditions such as those seen in Los Angeles where visual range often is reduced to a few kilometers. The model would be inappropriate for predicting visibility over great distances through nonuniform hazes and likewise is not suited to visualizing the effect of isolated major point source plumes.

While the above limitations are inherent in the trajectory model formulation, other limitations arise from practical decisions made about how to represent physical processes within the model. Aerosol nucleation and coagulation have not been included because, for the urban application examined here, condensational growth, aerosol thermodynamics, and fog chemistry dominate the evolution of the aerosol size distribution. The aerosol has been represented as an internal mixture (all particles of the same size assume the same aver- age composition), although this approximation can be relaxed at the expense of greater consumption of computer time. Particles are assumed to be homogeneous spheres, both for convenience during transport and optics calculations and for lack of detailed information on actual aerosol structure. While water uptake by inorganic aerosols is represented in the model, the possibly hygroscopic nature of some organic aerosols is not tracked, again for lack of information sufficient to represent such processes.

Finally, there are uncertainties that arise in the course of the model application that are due to uncertainties in the available model evaluation data sets. Uncertainties undoubtedly exist in the wind fields, mixing depth data, gaseous pollutant emissions and source activity data, and there will always be mismatches that occur when data taken at single ground-based monitoring sites are compared to the computed properties of the much larger air volume carried by the ground level cell in the present model. The combined effects of such errors can be judged, approximately, by examining the results of previous modeling studies of gas phase pollutants during the August 27-28 SCAQS episode that used the same meteorological and source activity data [Harley et al., 1993a, b; Harley and Cass, 1995]. In those prior studies, total nonmethane hydrocarbon concentrations were underestimated, with a bias of $-12 \%$ to $-26 \%, \mathrm{NO}_{2}$ was predicted with a bias of $+22 \%$, and ozone generally was underpredicted with a bias of $+1 \%$ to $-9 \%$. In addition to errors of this magnitude that arise from emissions, gas phase chemistry, and transport calculations, there are several needs for data specific to the aerosol modeling process where field data from the SCAQS experiment are limited. The initial conditions for aerosol size distributions and chemical composition are needed hourly for each air parcel trajectory, yet only typical initial conditions over the ocean are known. Both the $p H$ of fog and the fraction of iron and manganese present in specific valence states were not measured during this SCAQS episode and must be estimated from typical values measured previously in southern California. Finally, the spatial extent of fogs recorded by human observers does not match certain of the instrumental data on relative humidity. In these cases, model sensitivity studies were conducted to assess model response to a reasonable range of alternative values. As shown in Table 4, average fine particle sulfate concentrations decline by $24 \%$ if the spatial extent of the fog is reduced, and sulfate concentrations vary by about $\pm 42 \%$ as $p \mathrm{H}$ varies over the range $p \mathrm{H} 3.5-4.5$. When the $\mathrm{NaCl}$ content of the initial conditions is increased by $30 \%$, the $\mathrm{Na}^{+}$concentrations at Claremont are matched more closely, and aerosol nitrate concentrations increase slightly. When hydrocarbon emissions are increased by $50 \%$ in order to reduce the underestimation of peak ozone concentrations by the model, aerosol nitrate, ammonium, and secondary organic aerosol concentrations increase. Throughout all of these sensitivity tests, overall mean PM2.5 mass concentrations vary only over the range $59-68 \mu \mathrm{g} \mathrm{m}^{-3}$ compared to a base 
case model prediction of $62 \mu \mathrm{g} \mathrm{m}^{-3}$ and an observed mean of $61 \mu \mathrm{g} \mathrm{m}^{-3}$

\section{Conclusions}

A source-oriented model for air pollutant effects on visibility has been developed that can compute light scattering, light extinction, and estimated visual range directly from data on gas phase and primary particle phase air pollutant emissions from sources. The importance of such a model is that it can be used to compute the effect of emission control proposals on visibilityrelated parameters in advance of the adoption of such control programs.

The model has been assembled by embedding several aerosol process modules within the photochemical trajectory model previously developed for aerosol nitrate concentration predictions by Russell et al. [1983] and Russell and Cass [1986]. These modules describe the size distribution and chemical composition of primary particle emissions, the speciation of organic vapor emissions, atmospheric chemical reactions, transport of condensible material between the gas and the particle phases, fog chemistry, dry deposition, and atmospheric light scattering and light absorption. The aerosol size distribution and compositional data for primary emissions from sources are taken from a series of source tests conducted specifically for the purpose of supporting such a modeling effort.

Model predictions have been compared to observed values using 48-hour trajectories arriving at Claremont, California, at each hour of August 28, 1987, during the Southern California Air Quality Study. Concentrations of gas phase pollutants $\mathrm{NO}_{2}, \mathrm{HNO}_{3}$, and $\mathrm{NH}_{3}$ are reproduced closely by the model, while $\mathrm{O}_{3}$ concentrations are underpredicted, as has been the case for all previous $\mathrm{O}_{3}$ simulations at Claremont using the SCAQS emission data [see Harley et al., 1993a, b]. Average PM10 and PM2.5 particle mass concentrations and filter-based measurements of elemental carbon and organic material are reproduced well with a bias of less than $10 \%$ in each case. The bias between base case predictions and observed values of $\mathrm{PM} 2.5 \mathrm{SO}_{\overline{4}}$ concentrations is about $30 \%$. Predicted aerosol elemental carbon and $\mathrm{Na}^{+}$concentrations are each within $0.6 \mu \mathrm{g} \mathrm{m}^{-3}$ of the observed values on average. Aerosol ammonium and nitrate concentrations are underpredicted due to a shortage of total inorganic nitrate production by the model (i.e., less $\mathrm{HNO}_{3}$ is produced than it would take to match observed aerosol nitrate values). When vapor phase organics emissions into the model are increased further, as was done during sensitivity analysis, then both $\mathrm{O}_{3}$ and inorganic nitrate production increase, partly resolving the two discrepancies between observations and predictions.

Accurate prediction of the size distribution and chemical composition of the aerosol at Claremont is central to accurate predictions of light-scattering levels. The predicted aerosol size distribution and chemical composition generally capture the composition, volume, and shape of the measured submicron aerosol, and the correct volume of coarse particle material is predicted on average. As a result, model predictions and measurements of the atmospheric light-scattering coefficient agree with an average bias of $19 \%$.

In conclusion, a source-oriented model for the effects of air pollutants on visibility has been demonstrated that successfully predicts the level of atmospheric light scattering while starting with data on the emissions of primary pollutants at their source, followed by a mechanistic simulation of atmospheric chemistry and aerosol processes.

Acknowledgment. This research was supported by a grant from the Caltech Center for Air Quality Analysis.

\section{References}

Carmichael, G. R., L. K. Peters, and T. Kitada, A second generation model for regional-scale transport/chemistry/deposition, Atmos. Environ., 20, 173$188,1986$.

Carmichael, G. R., L. K. Peters, and R. D. Saylor, The STEM-II regional scale acid deposition and photochemical oxidant model, I, An overview of model development and applications, Atmos. Environ., 25, 2077-2090, 1991.

Carter, W. P. L., A detailed mechanism for the gas-phase atmospheric reactions of organic compounds, Atmos. Environ., 24A, 481-518, 1990.

Cass, G. R., On the relationship between sulfate air quality and visibility in Los Angeles, Environ. Qual. Lab. Memo. 18, Calif. Inst. of Technol., Pasadena, 1976.

Cass, G. R., On the relationship between sulfate air quality and visibility with examples in Los Angeles, Atmos. Environ., 13, 1069-1084, 1979.

Chang, E., K. Nolan, M. Dais, T. Chico, S. Chan, and E. Pang, Final appendix III-A, 1987 emissions inventory for the South Coast Air Basin: Average annual day, technical report, South Coast Air Qual. Manage. Dist., Diamond Bar, Calif., 1991.

Chang, J. S., S. A. Isaken, S. Madronich, P. Middleton, W. R. Stockwell, and C. J. Walcek, A three-dimensional Eulerian acid deposition model: Physical concepts and formulation, J. Geophys. Res., 92, 14,681-14,700, 1987.

Chang, J. S., et al., The regional acid deposition model and engineering model, Tech. Rep. NAPAP Rep. 4, Nat. Acid Precip. Assess. Program, Washington, D. C., 1991.

Cooper, J. A., D. C. Redline, J. R. Sherman, L. M. Valdovinos, L. C. Scavone, and C. Badgett-West, Final appendix V-G, PM10 source composition library for the South Coast Air Basin, technical report, South Coast Air Qual. Manage. Dist., Diamond Bar, Calif., 1989.

Eldering, A., Alternative models for air pollution effects on visibility, Ph.D. thesis, Calif. Inst. of Technol., Pasadena, 1994.

Eldering, A., P. A. Solomon, L. G. Salmon, T. Fall, and G. R. Cass, Hydrochloric acid: A regional perspective on concentrations and formation in the atmosphere of southern California, Atmos. Environ., 25A, 2091-2102, 1991.

Eldering, A., S. M. Larson, J. R. Hall, K. J. Hussey, and G. R. Cass, Development of an improved image processing based visibility model, Environ. Sci. Technol., 27, 626635, 1993.

Eldering, A., G. R. Cass, and K. C. Moon, An air monitoring network using continuous size distribution monitors: 
Connecting pollutant properties to visibility via Mie scattering calculations, Atmos. Environ., 28, 2733-2749, 1994.

Eltgroth, M. W., and P. V. Hobbs, Evolution of particles in the plumes of coal-fired power plants, II, A numerical model and comparisons with field measurements, Atmos. Environ., 13, 953-975, 1979.

Englehart, P. J., and G. E. Muleski, Final technical report III-F, inventory of PM10 emissions from fugitive dust sources in the South Coast Air Basin, technical report, South Coast Air Qual. Manage. Dist., Diamond Bar, Calif., 1991.

Erel, Y., S. O. Pehkonen, and M. R. Hoffmann, Redox chemistry of iron in fog and stratus clouds, J. Geophys. Res., $98,18,423-18,434,1993$

Fitz, D. R., M. Chan, G. R. Cass, D. R. Lawson, and L. Ashbaugh, A multi-component size-classifying aerosol and gas sampler for ambient air monitoring, paper presented at 82nd Annual Meeting, Air and Waste Manage. Assoc., Anaheim, Calif., 1989.

Gharib, S., and G. R. Cass, Ammonia emissions in the South Coast Air Basin, open file report 84-2, Environ. Qual. Lab., Calif. Inst. of Technol., Pasadena, 1984.

Goodin, W. R., G. J. McRae, and J. H. Seinfeld, A comparison of interpolation methods for sparse data: Application to wind and concentration fields, J. Appl. Meteorol., 18, 761-771, 1979.

Gordon, J. I., Daytime visibility, a conceptual review, $J$. Opt. Soc. Am., 1, 1324-1324, 1984.

Gray, H. A., Control of atmospheric fine primary carbon particle concentrations, $\mathrm{Ph} . \mathrm{D}$. thesis, Calif. Inst. of Technol., Pasadena, 1986.

Harley, R. A., and G. R. Cass, Modeling the atmospheric concentrations of individual volatile organic compounds, Atmos. Environ., 29, 905-922, 1995.

Harley, R. A., M. P. Hannigan, and G. R. Cass, Respeciation of organic gas emissions and the detection of excess unburned gasoline in the atmosphere, Environ. Sci. Technol., 26, 2395-2408, 1992.

Harley, R. A., A. G. Russell, and G. R. Cass, Mathematical modeling of the concentrations of volatile organic compounds: Model performance using a lumped chemical mechanism, Environ. Sci. Technol., 27, 1638-1649, 1993a.

Harley, R. A., A. G. Russell, G. J. McRae, G. R. Cass, and J. H. Seinfeld, Photochemical modeling of the Southern California Air Quality Study, Environ. Sct. Technol., 27, 378-388, 1993b.

Heisler, S. L., and S. K. Friedlander, Gas-to-particle conversion in photochemical smog: Aerosol growth laws and mechanisms for organics, Atmos. Environ., 11, 157-168, 1977.

Hering, S. V., and S. K. Friedlander, Origins of aerosol sulfur size distributions in the Los Angeles basin, Atmos. Environ., 16, 2647-2656, 1982.

Hering, S. V., et al., The nitric acid shootout: Field comparison of measurement methods, Atmos. Environ., 22, $1519-1539,1988$.

Hildemann, L. M., G. R. Cass, and G. R. Markowski, A dilution stack sampler for collection of organic aerosol emissions: Design, characterization and field tests, Aerosol Scr. Technol., 10, 193-204, 1989.

Hildemann, L. M., G. R. Markowski, and G. R. Cass, Chemical composition of emissions from urban sources of fine organic aerosol, Environ. Sci. Technol., 25, 744-759, 1991a.

Hildemann, L. M., G. R. Markowski, M. C. Jones, and G. R. Cass, Submicrometer aerosol mass distributions of emissions from boilers, fireplaces, automobiles, diesel trucks, and meat-cooking operations, Aerosol Sci. Technol., 14, 138-152, 1991b.
Hodkinson, J. R., Calculations of color and visibility in urban atmospheres polluted by gaseous $\mathrm{NO}_{2}$, Air Water Pollut. Int. J., 10, 137-144, 1966.

Hoffmann, M. R., and J. G. Calvert, Chemical transformation modules for Eulerian and deposition models, vol. II; in The Aqueous Phase Chemistry, Tech. Rep. EPA 600/385/036, Environ. Prot. Agency, Research Triangle Park, N.C., 1985.

Houck, J. E., J. C. Chow, J. G. Watson, C. A. Simons, L. C. Pritchett, J. M. Goulet, and C. A. Frazier, Determination of particle size distribution and chemical composition of particulate matter from selected sources in California, technical report, Calif. Air Resour. Board, contract A6175-32, OMNI Environ. Serv., Inc., and Desert Res. Inst., Beaverton, Oregon, 1989.

Hudischewskyj, A. B., and C. Seigneur, Mathematical modeling of the chemistry and physics of aerosols in plumes, Environ. Scr. Technol., 23, 413-421, 1989.

Ingalls, M. N., On-road vehicle emission factors from measurements in a Los Angeles area tunnel, paper presented at the 82nd Annual Meeting, Air and Waste Manage. Assoc., Anaheim, Calif., 1989.

Jacob, D. J., J. M. Waldman, J. W. Munger, and M. R. Hoffmann, Fogwater chemistry in an urban atmosphere, Environ. Scı. Technol., 19, 730-736, 1985.

John, W., S. M. Wall, J. L. Ondo, and W. Winklmayr, Acidic aerosol size distributions during SCAQS, technical report, contract A6-112-39, Calif. Air Resour. Board, Sacramento, Calif., 1989.

Lamb, R. G., A regional scale $(100 \mathrm{~km})$ model of photochemical air pollution, 1, Theoretical formulation, EPA Tech. Rep., Environ. Prot. Agency, Research Triangle Park, N. C., 1982.

Larson, S. M., G. R. Cass, K. J. Hussey, and F. Luce, Verification of image processing based visibility models, Envıron. Sci. Technol., 22, 629-637, 1988.

Lawson, D. R., The southern California air quality study, $J$. Air Waste Manage. Assoc., 40, 156-165, 1990.

$\mathrm{Li}$, W., and P. K. Hopke, Initial size distribution and hydroscopicity of indoor combustion aerosol particles, Aerosol Sci. Technol., 19, 305-316, 1993.

Liu, M. K., and J. H. Seinfeld, On the validity of grid and trajectory models of urban air pollution, Atmos. Environ., 9, 555-574, 1975

Liu, M. K., R. E. Morris, and J. P. Killus, Development of a regional oxidant model and application to the northeastern United States, Atmos. Environ., 18, 1145-1161, 1984.

MacCracken, M. C., D. J. Wuebbles, J. J. Walton, W. H. Duewer, and K. E. Grant, The Livermore regional air quality model, I, Concept and development, J. Appl. $\mathrm{Me}$ teorol., 17, 254-272, 1978.

McMurry, P. H., and J. C. Wilson, Droplet phase (heterogeneous) and gas phase (homogeneous) contributions to secondary ambient aerosol formation as functions of relative humidity, J. Geophys. Res., 8, 5101-5108, 1983.

McRae, G. J., W. R. Goodin, and J. H. Seinfeld, Development of a second-generation mathematical model for urban air pollution, I, Model formulation, Atmos. Environ., $16,679-696,1982$.

Meng, Z., and J. H. Seinfeld, On the source of the submicron droplet mode of urban and regional aerosols, Aerosol Sci. Technol., 20, 253-265, 1994.

Middleton, W. E. K., Vision Through the Atmosphere. Univ. of Toronto Press, Ontario, Canada, 1952.

Middleton, P., and S. Burns, Denver air quality modeling study, paper presented at the Annual International Meeting, Air and Waste Manage. Assoc., Vancouver, B. C., Canada, 1991. 
Mozurkewich, M., The dissociation constant of ammonium nitrate and its dependence on temperature, relative humidity and particle size, Atmos. Environ., 27A, 261-270, 1993.

Munger, J. W., D. J. Jacob, J. M. Waldman, and M. R. Hoffmann, Fogwater chemistry in an urban atmosphere, J. Geophys. Res., 88, 5109-5121, 1983.

National Research Council (NRC), Protectıng Visıbility in National Parks and Wilderness Areas, Nat. Acad. Press, Washington, D. C., 1993.

Pandis, S. N., and J. H. Seinfeld, Sensitivity analysis of a chemical mechanism for aqueous phase atmospheric chemistry, J. Geophys. Res., 94, 1105-1126, 1989.

Pandis, S. N., R. A. Harley, G. R. Cass, and J. H. Seinfeld, Secondary organic aerosol formation and transport, Atmos. Environ., 26A, 2269-2282, 1992a.

Pandis, S. N., J. H. Seinfeld, and C. Pilinis, Heterogeneous sulfate formation in an urban fog, Atmos. Environ., 26A, 2509-2522, 1992b.

Pandis, S. N., A. S. Wexler, and J. H. Seinfeld, Secondary organic aerosol formation and transport, II, Predicting the ambient secondary organic aerosol size distribution, Atmos. Environ., 27A, 2403-2416, 1993.

Penndorf, R., Tables of the refractive index for standard air and the Rayleigh scattering coefficient for the spectral region between 0.2 and $20.0 \mu \mathrm{m}$ and their application to atmospheric optics, J. Opt. Soc. Am., 47, 176-182, 1957.

Penner, J. E., and P. S. Connell, Pollutant transport study: Bay area to north central coast air basin, technical report, Calif. Air Resour. Board, Sacramento, Calif., 1987.

Pierson, W. R., A. W. Gertler, and R. L. Bradow, Comparison of the SCAQS tunnel study with other on-road vehicle emission data, J. Air Waste Manage. Assoc., 40, 1495-1504, 1990.

Pilinis, C., and J. H. Seinfeld, Continued development of a general equilibrium model for inorganic multicomponent atmospheric aerosols, Atmos. Environ,, 21, 2453-2466, 1987.

Pilinis, C., and J. H. Seinfeld, Development and evaluation of an Eulerian photochemical gas-aerosol model, Atmos. Environ., 22, 1985-2001, 1988.

Pilinis, C., J. H. Seinfeld, and C. Seigneur, Mathematical modeling of the dynamics of multicomponent atmospheric aerosols, Atmos. Environ., 21, 943-955, 1987.

Pitchford, M., and A. Pitchford, Analysis of regional visibility in the southwest using principal component and back trajectory analysis, Atmos. Environ., 19, 1301-1316, 1985.

Pruppacher, H. R., and J. D. Klett, Microphysics of Clouds and Precipitation. D. Reidel, Norwell, Mass., 1978.

Reynolds, S. D., P. M. Roth, and J. H. Seinfeld, Mathematical modeling of photochemical air pollution, I, Formulation of the model, Atmos. Environ., 7, 1033-1061, 1973.

Reynolds, S. D., L. Reid, M. Hillyer, J. P. Killus, T. E. Tesche, R. I. Pollack, G. E. Anderson, and J. Ames, Photochemical modeling of transportation control strategies: Model development, performance evaluation and strategy assessment, technical report, U. S. Dep. of Transp., Fed. Highway Admin., Off. of Res., Washington, D. C., 1979.

Russell, A. G., and G. R. Cass, Verification of a mathematical model for aerosol nitrate and nitric acid formation and its use for control measure evaluation, Atmos. Environ., 20, 2011-2025, 1986.

Russell, A. G., G. J. McRae, and G. R. Cass, Mathematical modeling of the formation and transport of ammonium nitrate aerosol, Atmos. Environ., 17, 949-964, 1983.

Russell, A. G., G. J. McRae, and ( R. Cass, Acid deposition of photochemical oxidation products-A study using a Lagrangian trajectory model, in Air Pollution Modeling and Its Application III, edited by C. deWispelaere, pp. 539-564. Plenum, New York, 1984.

Russell, A. G., K. F. McCue, and G. R. Cass, Mathematical modeling of the formation of nitrogen-containing air pollutants, 1, Evaluation of an Eulerian photochemical model, Environ. Sci. Technol., 22, 263-271, 1988.

Saxena, P., C. Seigneur, A. B. Hudischewskyj, and J. H. Seinfeld, A comparitive study of equilibrium approaches to the chemical characterization of secondary aerosols, $A t$ mos. Environ., 1986, 1471-1484, 1986.

Seigneur, C., The status of mesoscale air quality models, in Planning and Managing Regional Air Quality - Modeling and Measurement Studies, edited by P. A. Solomon, Pp. 403-433, Lewis, Boca Raton, Fla., 1994.

Seigneur, C., T. W. Tesche, P. M. Roth, and M. K. Liu, On the treatment of point source emissions in urban air quality modeling, Atmos. Environ., 17, 1655-1676, 1983.

Seigneur, C., R. W. Bergstrom, C. D. Johnson, and L. W. Richards, Measurements and simulations of the visual effects of particulate plumes, Atmos. Envıron., 18, 2231$2244,1984$.

Seinfeld, J. H., Atmospheric Chemistry and Physics of Air Pollution. John Wiley, New York, 1986.

Slinn, S. A., and W. G. N. Slinn, Predictions for particle deposition on natural waters, Atmos. Environ., 14, 10131016, 1980.

Sloane, C. S., Optical properties of aerosols of mixed composition, Atmos. Environ., 18, 871-878, 1984.

Sloane, C. S., Contribution of $\mathrm{NO}_{2}$ and soot to the discoloration of urban skies, Atmos. Environ., 22, 2021-2031, 1988.

Solomon, P. A., S. M. Larson, T. Fall, and G. R. Cass, Basinwide nitric acid and related species concentrations observed during the Claremont nitrogen species comparison study, Atmos. Environ., 22, 1587-1594, 1988.

Stelson, A. W., Urban aerosol refractive index prediction by partial molar refraction approach, Environ. Scı. Technol., 24, 1676-1679, 1990.

Stevens, R. K., T. G. Dzubay, C. W. Lewis, and R. W. Shaw, Source apportionment methods applied to the determination of the origin of ambient aerosols that affect visibility in forested areas, Atmos. Environ., 18, 261-272, 1984.

Taback, H. J., A. R. Brienza, J. Macko, and N. Brunetz, Fine particle emissions from stationary and miscellaneous sources in the South Coast Air Basin, technical report, Calif. Air Resour. Board, contract A6-191-30, KVB, Inc., Research-Cottrell, Tustin, Calif., 1979.

van de Hulst, H. C., Light Scattering by Small Particles. John Wiley, New York, New York, 1957.

Venkatram, A., P. K. Karamchandani, and P. K. Misra, Testing a comprehensive acid deposition model, Atmos. Environ., 22, 737-747, 1988.

Waldman, J. M., Depositional aspects of pollutant behavior in fog, Ph.D. thesis, Calif. Inst. of Technol., Pasadena, 1985.

Wexler, A. S., and J. H. Seinfeld, Second-generation inorganic aerosol model, Atmos. Environ., 25A, 2731-2748, 1991.

White, W. H., C. Seigneur, D. W. Heinhold, M. W. Eltgroth, L. W. Richards, P. T. Roberts, P. S. Bhardwaja, W. D. Conner, and W. E. Wilson, Predicting the visibility of chimney plumes: An intercomparison of four models with observations at a well-controlled power plant, Atmos. Environ., 19, 515-528, 1985.

Whitten, G. Z., H. Hogo, and J. P. Killus, The carbon-bond mechanism: A condensed kinetic mechanism for photochemical smog, Environ. Scr. Technol., 14, 690-700, 1980.

Yamartino, R. J., J. S. Scire, G. R. Carmichael, and Y. S. Chang, The CALGRID mesoscale photochemical grid 
model, I, Model formulation, Atmos. Environ., 26A, 14931512, 1992.

Young, T., and J. Boris, A numerical technique for solving stiff ordinary differential equations associated with the chemical kinetics of reactive flow problems, J. Phys. Chem., 81, 2424-2427, 1977.

Zannetti, P., I. Tombach, and W. Balson, Calculation of visual range improvements from $\mathrm{SO}_{2}$ emission controlsI, Semi-empirical methodology, Atmos. Environ., 24 A, 2361-2368, 1990.

Zannetti, P., I. Tombach, and S. Cvencek, Calculation of visual range improvements from $\mathrm{SO}_{2}$ emission controls-II, Application to the eastern United States, Atmos. Environ., 27A, 1479-1490, 1993.
Zhang, X. Q., P. H. McMurry, S. V. Hering, and G. S. Casuccio, Mixing characteristics and water content of submicron aerosols measured in Los Angeles and at the Grand Canyon, Atmos. Environ., 27A, 1593-1607, 1993.

G. R. Cass (corresponding author), Environmental Engineering Science Department, California Institute of Technology, Mail Code 138-78, Pasadena, CA 91125.

A. Eldering, Civil and Environmental Engineering, 2128EB, University of Iowa, Iowa City, IA 52242.

(Received October 31, 1994; revised June 9, 1995; accepted August 18, 1995.) 